\title{
Tangential streaming potential, transmembrane flux, and chemical cleaning of ultrafiltration
}

membranes

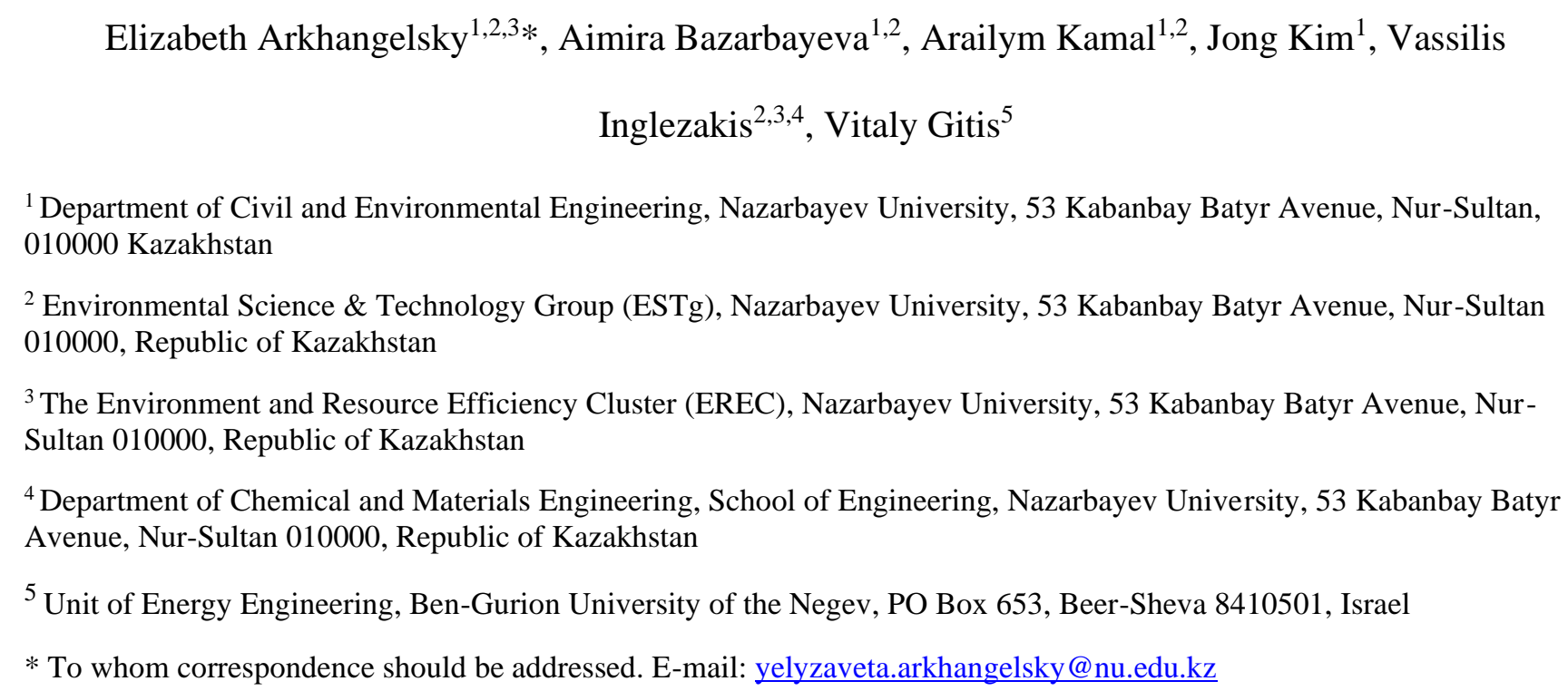

\section{Abstract}

Transmembrane flux measurements are the only practical tools used to evaluate the degree of organic fouling and the efficiency of chemical cleaning of ultrafiltration membranes in situ. Tangential pH-streaming potential profiles may become a comprehensive in situ method to analyse cleaning efficiency versus potential membrane damage. A parallel implementation of the two methods was used to assist in tuning an efficient cleaning protocol for $300 \mathrm{kDa}$ polyethersulfone membranes. The membranes were fouled with a mixture of organics and cleaned with nitric acid, acetic acid, caustic soda or liquid bleach, each at concentrations of 1, 5, or $10 \mathrm{mg} / \mathrm{L}$. A modified Kolmogorov-Smirnov test for divergence in datasets clearly indicated cleaning with $5 \mathrm{mg} / \mathrm{L} \mathrm{NaOH}$ or $\mathrm{NaOCl}$. These findings were confirmed by atomic force microscopy surface contouring and infrared spectra recording.

Tangential pH-streaming potential profiling is easy in terms of operation and maintenance, inexpensive, and may be conducted in situ. Implementation of two independent tests is instrumental in the validation of the cleaning agent efficiency, optimisation of the cleaning dose and $\mathrm{pH}$, and assessment of membrane fouling potential by complex organic mixtures. A combination of transmembrane flux and tangential streaming potential tests may reduce the cost of chemical cleaning and suspend membrane ageing. 
32 Keywords: Ultrafiltration; Polyethersulfone; Atomic force microscopy; Attenuated total reflection 33 Fourier-transform infrared spectroscopy; Transmembrane pressure 


\section{Introduction}

Ultrafiltration (UF) membranes are routinely implemented to purify proteins for pharmaceutical and biotechnological needs [1,2]. The operation is typically conducted with polymer membranes that gradually become fouled by proteins. Maintaining a good protein yield and membrane selectivity requires the periodic cleaning of the fouled membranes. Physical cleaning is applied regularly to hydraulically remove reversible foulants via surface and back washing. Foulants lodged on the membrane surface after hydraulic cleaning are removed by chemical cleaning. Efficient chemical cleaning requires a suitable cleaning agent specific to the type of foulant. Acids are used to dissolve inorganic precipitates, bases are used for the hydrolysis of proteins, and oxidants are used for the oxidation of organics. Complex fouling is treated through a sequence of cleaning agents, as prescribed in cleaning protocols. The protocols are typically generic, derived empirically, kept within a chemical company, and rarely optimised [3]. The ultimate goal is to efficiently clean the membrane within a short period of time. To achieve this, high concentrations of cleaning agents and short contact times are usually implemented [4]. To increase cleaning efficiency, a protocol typically recommends 1) increasing the concentration of the cleaning agent, or 2) increasing the time/frequency of chemical cleaning, or 3) using more aggressive cleaning agents, or 4) magnifying the transmembrane pressure. The solutions are expensive (extended energy and water consumption, reduced production time), impact upon membrane integrity or accelerate its ageing, and ultimately impair the filtrate quality [5]. A treatment facility is then forced to replace the damaged membranes with new membranes sooner than would have been the case if an optimised cleaning protocol had been implemented. The replacement increases the operational expenses of membrane operation and the cost of the purified product.

The exact cleaning protocol has one major weakness; the evaluation of cleaning efficiency. A properly cleaned membrane should be intact and not exhibit any chemical or microbiological residues on its surface or within the matrix. In general, visual observations of the membrane surface, studies of its chemical composition by infrared (FTIR) spectroscopy, X-ray photoelectron (XPS) spectroscopy, energy dispersive X-ray (EDX) spectroscopy, or bacteriological tests for microbial fouling, are conducted in situ using sophisticated equipment and are avoided. There are two in situ analyses that are routinely conducted to assess the efficiency of chemical cleaning; hydraulic and bubble point tests. The bubble point test [6] verifies the appearance of pores larger than $1 \mu \mathrm{m}$, while the hydraulic test usually determines cleaning efficiency as a ratio of transmembrane fluxes through a fouled and a pristine membrane. A hydraulically clean membrane is the one that shows an arbitrary ratio of 0.65 
[7], 0.87 [8], 0.95 [9-12], or any other number that may eventually be even higher than 1.0. And still,, a membrane can demonstrate complete flux recovery while foulants are deployed on its surface and within the matrix [13]. Aggressive chemical cleaning, particularly if the membrane is fouled by organic matter, affects the bonds between the foulants and the membrane. As the membrane and the residue are of organic origin, the cleaning agent often oxidises the membrane itself. Membrane oxidation increases its hydrophilicity, surface charge, and pore size [14]. An increased hydrophilicity or surface charge will compensate for partial flux loss due to irreversible fouling, especially during the initial stages of its development. Inaccurate assessment based on insufficient knowledge leads to continued membrane operation despite the membrane being partially fouled. Potential organic foulants use existing fouled sites as stepping stones for further invasion of the membrane surface until there is excessive coverage. At this stage, the flux cannot be recovered, and the membrane needs to be replaced. This situation may be prevented if an additional in situ non-invasive test would properly interpret the assessment of membrane status and the chemical cleaning effectiveness. Although the hydraulic test is essential, it alone is insufficient.

This study suggests an additional in situ monitoring technique to understand the chemical cleaning acquired by flux measurements. The streaming potential originates when an electrolyte solution moves over a charged surface, and the motion is induced by a hydrostatic pressure gradient. The measurements are non-destructive and may be conducted either by forcing the electrolyte through the membrane pores (transmembrane streaming potential) or alongside the membrane surface (tangential streaming potential). This approach is not novel and has been widely discussed more than a decade ago [15-23]. However, the approach has not been advanced as studies suggested measuring a transmembrane streaming potential when the flow was directed perpendicular to the active membrane layer. In case of cake formation as the main fouling mechanism, measurements do not reflect the real properties of the cake layer, as the membrane itself plays a non-negligible role [24]. Studies that reported tangential streaming potential measurements used impractically high concentrations of cleaning agents $[25,26]$ and mainly reported on changes in the streaming potential values as a result of cleaning. The use of tangential streaming potential sequencing to optimise the dose of a cleaning agent has not previously been reported in the literature.

To the best of our knowledge, the capacities of the tangential streaming potential have not been fully explored, particularly to distinguish between a clean and an affected membrane. A sufficiently cleaned membrane exhibits a tangential $\mathrm{pH}$-streaming potential profile close to that of a virgin membrane. If the flux through a cleaned membrane is equal to its initial value, but the $\mathrm{pH}$-streaming 
potential profile is different from that of a virgin membrane, the membrane is damaged or has not been sufficiently cleaned. Confirmation of this hypothesis will equate the definition of a hydraulically clean membrane with the definition of a chemically cleaned membrane. It is important to remember that industrial users are interested in methods that are in situ, inexpensive, and easy to operate and implement. Streaming potential has the capacity to become a fundamental tool to monitor chemical cleaning and provide necessary feedback control of its efficiency. The proposed test is suitable for a variety of UF separation processes, including water and wastewater treatment. Efficient implementation of the proposed monitoring technique will require tuning based on the nature of the filter cake that will be formed during the process.

\section{Materials and methods}

\subsection{Membrane preparation and characterisation}

New $300 \mathrm{kDa}$ polyethersulfone (PES) membranes (Sterlitech Corporation, USA) were used. Prior to the first use, membranes were shaken in a shaker at $37{ }^{\circ} \mathrm{C}$ for $1 \mathrm{~h}$. The shaking resulted in similar feed and permeate total organic carbon (TOC) levels during the filtration of deionised water (DIW, MilliQ quality). Zeta potential was measured using a SurPASS electrokinetic analyser (Anton Paar GmbH, Austria). The $\mathrm{pH}$ was varied from 2 to 10 automatically, and each specific zeta potential value was measured twice. DIW was used to prepare the electrolytes, and all solutions used to regulate ionic strength $(\mathrm{KCl})$ and $\mathrm{pH}(\mathrm{KOH}, \mathrm{HCl})$ were of analytical grade. The membrane contact angle was measured with an optical contact angle (OCA) 25 (DataPhysics Instruments GmbH, Germany) contact angle metre using sessile DIW drops. Eight to ten measurements with separate membrane pieces per sample were conducted. The reported values were the arithmetic means of all measurements. Attenuated total reflectance Fourier-transform infrared (ATR-FTIR) spectra were obtained using a Cary 660 FTIR spectrometer (Agilent, USA); all spectra were recorded at ambient temperature. The instrument was purged with dry nitrogen to prevent the interference of atmospheric moisture. Membrane samples were kept in closed Petri dishes filled with water and blotted dry prior to analysis. Excess water was removed by drying in a desiccator over $\mathrm{P}_{2} \mathrm{O}_{5}$ for $2 \mathrm{~h}$. Wavenumbers between 400 and $4000 \mathrm{~cm}^{-1}$ were recorded with a $4 \mathrm{~cm}^{-1}$ resolution. Atomic force microscopy (AFM) SartSPM 1000 (AIST-NT Inc., USA) was used for visual analysis of membrane surfaces.

\subsection{Filtration experiments}

Filtration experiments were conducted in a CF016 cross-flow stainless steel cell (Sterlitech Corporation, USA) with a $16 \mathrm{~cm}^{2}$ internal filtration area; Figure 1 illustrates the experimental setup. 


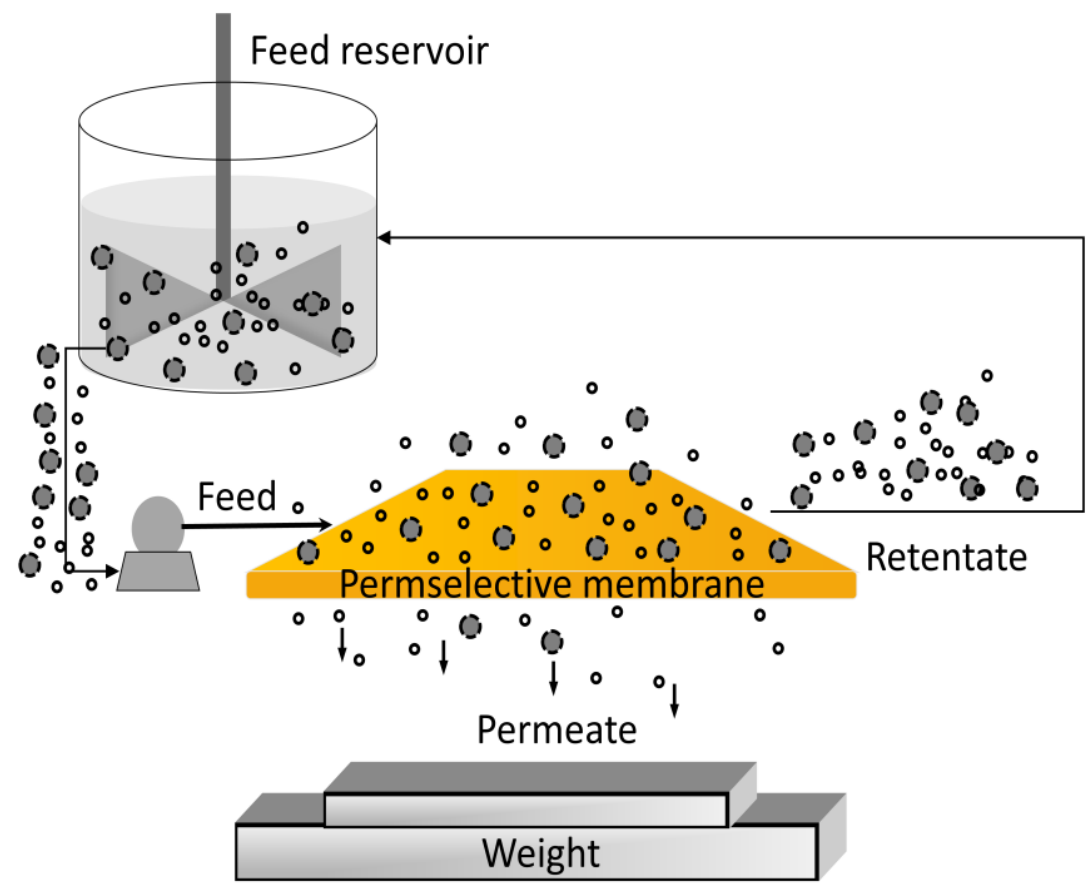

Figure 1. Filtration cell setup.

Feed was supplied with a peristaltic pump (Cole -Parmer USA). The membranes were first compacted for $30 \mathrm{~min}$ at $70 \mathrm{~L} / \mathrm{m}^{2} \mathrm{~h}(\mathrm{LMH})$ transmembrane flux of DIW. The $60 \mathrm{~min}$ filtration cycles at a constant transmembrane pressure (TMP) of 1.9 bar were conducted with $0.6 \mathrm{~g} / \mathrm{L}$ Similac 1 baby formula (Abbott Laboratories, USA) mixed in DIW. According to the manufacturer, the feed contains $65 \mathrm{mg} / \mathrm{L}$ total proteins, $158 \mathrm{mg} / \mathrm{L}$ fat, and $348 \mathrm{mg} / \mathrm{L}$ carbohydrates. The transmembrane flux was calculated gravimetrically as per Equation (1):

$$
J=\frac{\Delta m}{\rho S \Delta t}
$$

where $\Delta m$ is the permeate weight difference $(\mathrm{kg})$ measured with a digital balance (Kern, Germany); $\Delta t$ is the frequency interval (h); $S$ is the active membrane surface area $\left(0.0016 \mathrm{~m}^{2}\right)$; and $\rho$ is the permeate density $\left(\sim 1000 \mathrm{~kg} / \mathrm{m}^{3}\right)$. Changes in flux due to cake formation were calculated as per Equation (2) [27]:

$$
J / J_{0}=\left(1+\frac{2 \alpha S t}{\mu R_{M}^{2}} T M P\right)^{-1 / 2}
$$

where $J_{0}$ is the flux through a pristine membrane; $\alpha$ is a parameter characterising the fouling potential of the solution $\left(4.5-6.5 \cdot 10^{5} \mathrm{~m}^{-4}\right) ; \mu$ is the dynamic viscosity of water $\left(10^{-3} \mathrm{~kg} / \mathrm{m} \cdot \mathrm{s}\right)$; and TMP is 
$1.9 \cdot 10^{5} \mathrm{~Pa}$. The intrinsic membrane resistance $R_{M}\left(1.1 \cdot 10^{13} \mathrm{~m}^{-1}\right)$ was calculated using Equation (3) [28]:

$$
R_{M}=\frac{T M P}{\mu J_{0}}
$$

The changes in flux due to internal pore plugging [27] assume that the membrane pores are plugged due to the deposition or adsorption of organics within the pores:

$$
J / J_{0}=\left(1+\frac{J_{0} \beta t}{\varepsilon \lambda}\right)^{-2}
$$

where $\varepsilon(0.16)$ is membrane porosity; $\lambda\left(10^{-7} \mathrm{~m}\right)$ is membrane thickness; and $\beta\left(1.4-2.5 \cdot 10^{-10}\right)$ is a dimensionless parameter that determines the potential for the solution to provoke internal fouling.

\subsection{Membrane cleaning}

Membrane cleaning was conducted with 1,5 , and $10 \mathrm{mg} / \mathrm{L}$ of nitric acid $\left(\mathrm{HNO}_{3}\right)$, acetic acid $\left(\mathrm{CH}_{3} \mathrm{COOH}\right)$, caustic soda $(\mathrm{NaOH})$, or liquid bleach $(\mathrm{NaOCl})$. All chemicals were obtained from Sigma Aldrich and were used as received. The cleaning in place (CIP) operation was a $5 \mathrm{~min}$ procedure, and the calculated $C t$ values were 5,25 , and $50 \mathrm{mg} \cdot \mathrm{min} / \mathrm{L}$. After $5 \mathrm{~min}$, membranes were rinsed with DIW. The efficiency of chemical cleaning was assessed by relative flux calculated as $J_{0, \text { clean }} / J_{0, \text { virgin }}$ where $J_{0, \text { clean }}$ and $J_{0, \text { virgin }}$ are the fluxes through a chemically cleaned and a virgin membrane, respectively. The flux values are aggregate DIW fluxes recorded during the first $5 \mathrm{~min}$ of the filter run. The flux during this time was stable and indicated an absence of significant fouling or compaction.

In addition, cleaning efficiency was evaluated by interpreting the Kolmogorov-Smirnov test [29] for the highest dissimilarities in the data recorded through flux or zeta potential measurements. The dissimilarities were calculated by 1) separate calculations of the aggregate values of each dataset;2) calculations of differences between two independent datasets at each measurement point; and 3) identifying the largest difference point between the two datasets. These steps were aimed at determining the extent to which the two datasets were different from one another. In flux calculations, a separate dataset was used for filtration with DIW, and six datasets were used corresponding to $6 \mathrm{~h}$ of operation. Chemical cleaning after each hour was conducted, and we were able to determine the flux after each cleaning and how close this was to the flux obtained after the initial fouling. A close replication of fouling cycles indicated that the membrane surface had been sufficiently cleaned to perform in exactly the same manner. A significant deviation in flux values indicates that the membrane 
has not been sufficiently cleaned, or that it has been damaged by overcleaning and will be prone to more significant fouling in the next run.

The zeta potential dissimilarity curves were calculated by comparing the difference in the zeta potential values of pristine, fouled, and cleaned membranes. Higher dissimilarity indicates that the zeta potential curves of virgin and cleaned membranes are significantly different from each other. A close replication of zeta potential values indicates that the membrane was properly cleaned. A significant deviation suggests insufficient cleaning or overcleaning that may damage the membrane. In addition, this information was used to distinguish two datasets with very similar flux data patterns.

\subsection{Square-wave method to determine critical flux}

The reversibility of fouling is dependent on the foulant flux towards the membrane surface. Below a certain value, known as the critical flux, fouling is reversible. Above the critical flux, fouling is irreversible. The critical flux is the minimum flux that causes irreversible fouling on the membrane surface [30,31]. Constant TMP during filtration at constant flux, or repeatable TMP profiles following physical cleaning, indicates that the flux is below critical. The inability to stabilise TMP during filtration, or higher initial TMP immediately after physical cleaning, signifies that fouling is irreversible. Thus, filtration in the reversible fouling domain implies a linear correlation between the flux and the TMP. A stepwise increase in the TMP results in a higher flux, while a stepwise decrease in the TMP should set the flux to previously measured values. This hypothesis is central to the squarewave filtration method [32,33]. Stepwise increases and reductions in the TMP produce the same flux profiles in the reversible fouling domain for the same TMP values. The inability to reproduce a previous profile indicates that the flux is above critical. This method is useful in fouling experiments to accurately assess the critical flux value using stepwise TMP alterations with positive and negative variations. The essentials of the test are depicted in Figure 2.

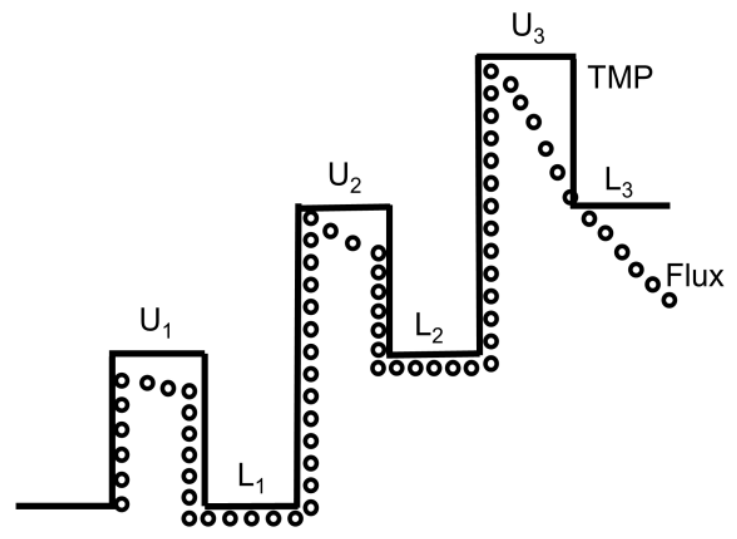


Figure 2. Principle of the square-wave method with stepwise pressure changes to upper $\left(\mathrm{U}_{1}, \mathrm{U}_{2}, \mathrm{U}_{3}\right)$ and lower $\left(\mathrm{L}_{1}, \mathrm{~L}_{2}, \mathrm{~L}_{3}\right)$ values. Pressure values are denoted by the solid lines, and the flux values are denoted by the dots. This scheme is modified from [32].

In Figure 2, the flux at the upper TMP levels, $\mathrm{U}_{1}$ and $\mathrm{U}_{2}$, is reversible, while the flux at $\mathrm{U}_{3}$ is irreversible. A test begins at a low constant TMP $\mathrm{L}_{1}$ and shifts to a higher pressure $\left(\mathrm{U}_{1}\right)$, after a few minutes. If the initial flux at $\mathrm{U}_{1}$ is lower than at $\mathrm{L}_{1}$, fouling is irreversible. If the flux at $\mathrm{U}_{1}$ is higher than at $\mathrm{L}_{1}$, the test continues for several minutes, and the TMP is shifted back to $\mathrm{L}_{1}$. If the flux $\mathrm{L}_{1}$ after $\mathrm{L}_{1}-\mathrm{U}_{1}-\mathrm{L}_{1}$ sequence is stable and comparable to the flux at the first $\mathrm{L}_{1}$, the fouling is reversible. Then, the test proceeds to a higher TMP $\mathrm{U}_{2}$ value, and continues until the flux enters the irreversible fouling domain.

\section{Results}

The critical flux was determined using the square-wave method described in Section 2.4. Figure 3 depicts the evolution of fluxes and TMPs during the test.

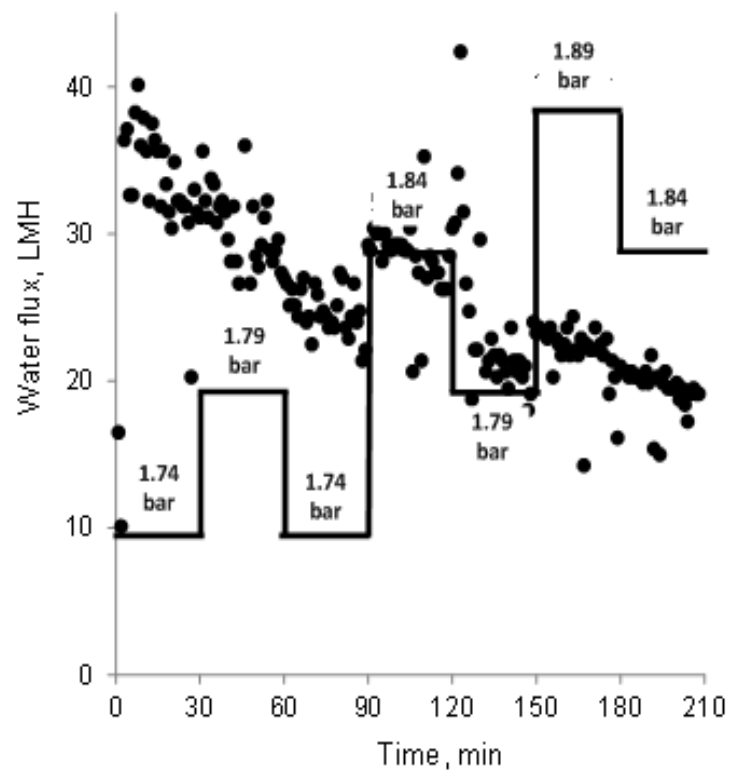

Figure 3. Evolution of flux and TMP during the irreversibility test. A continuous line represents the applied TMP, and the dotted line represents the permeate flux.

During the first $30 \mathrm{~min}$, the experiment was conducted at 1.74 bar TMP. The initial flux level of 10 LMH was replaced by a maximum of $40 \mathrm{LMH}$ immediately after 5 min of filtration. Further, the flux fluctuated between 40 and $30 \mathrm{LMH}$ for the entire period. Values close to $40 \mathrm{LMH}$ were observed at the beginning of the run; they shifted towards $30 \mathrm{LMH}$ at the end of the first period. After 30 min, the 
219 TMP was shifted to 1.79 bar, although the expected increase in the flux was not observed. The flux 220 slowly decreased from $30 \mathrm{LMH}$ near the beginning of the shift to $25 \mathrm{LMH}$ towards the end of the 221 filtration period. The same values were measured when the TMP was shifted back to 1.74 bar. A shift to 1.84 bar increased the flux towards $30 \mathrm{LMH}$ with sporadic values close to $40 \mathrm{LMH}$. The shift back to 1.79 bar displayed steady values around $20 \mathrm{LMH}$. A further increase towards 1.89 bar did not result 224 in a further increase in the flux; it remained stable around $20 \mathrm{LMH}$ for the 1.89 and 1.84 bar periods. 225 Therefore, we concluded that 1.89 bar TMP is above the critical flux, and conducted further filter runs at 1.9 bar TMP.

A typical filtration experiment is a sequence of six cycles; each cycle includes $1 \mathrm{~h}$ of PES 300 fouling and $5 \mathrm{~min}$ of chemical cleaning. The fouling was achieved using $0.6 \mathrm{~g} / \mathrm{L}$ Similac 1 baby formula that contained $65 \mathrm{mg} / \mathrm{L}$ total proteins, $158 \mathrm{mg} / \mathrm{L}$ fat, and $348 \mathrm{mg} / \mathrm{L}$ carbohydrates. The cleaning was conducted with 1,5 , and $10 \mathrm{mg} / \mathrm{L} \mathrm{HNO}_{3}, \mathrm{CH}_{3} \mathrm{COOH}, \mathrm{NaOH}$, or $\mathrm{NaOCl}$. Virgin, fouled, and cleaned membranes were characterised by flux, zeta potential, contact angle, ATR-FTIR, and AFM. Figures 4 and 5 depict the flux changes of a fouled membrane cleaned by $\mathrm{HNO}_{3}, \mathrm{CH}_{3} \mathrm{COOH}$, $\mathrm{NaOH}$, and $\mathrm{NaOCl}$. 

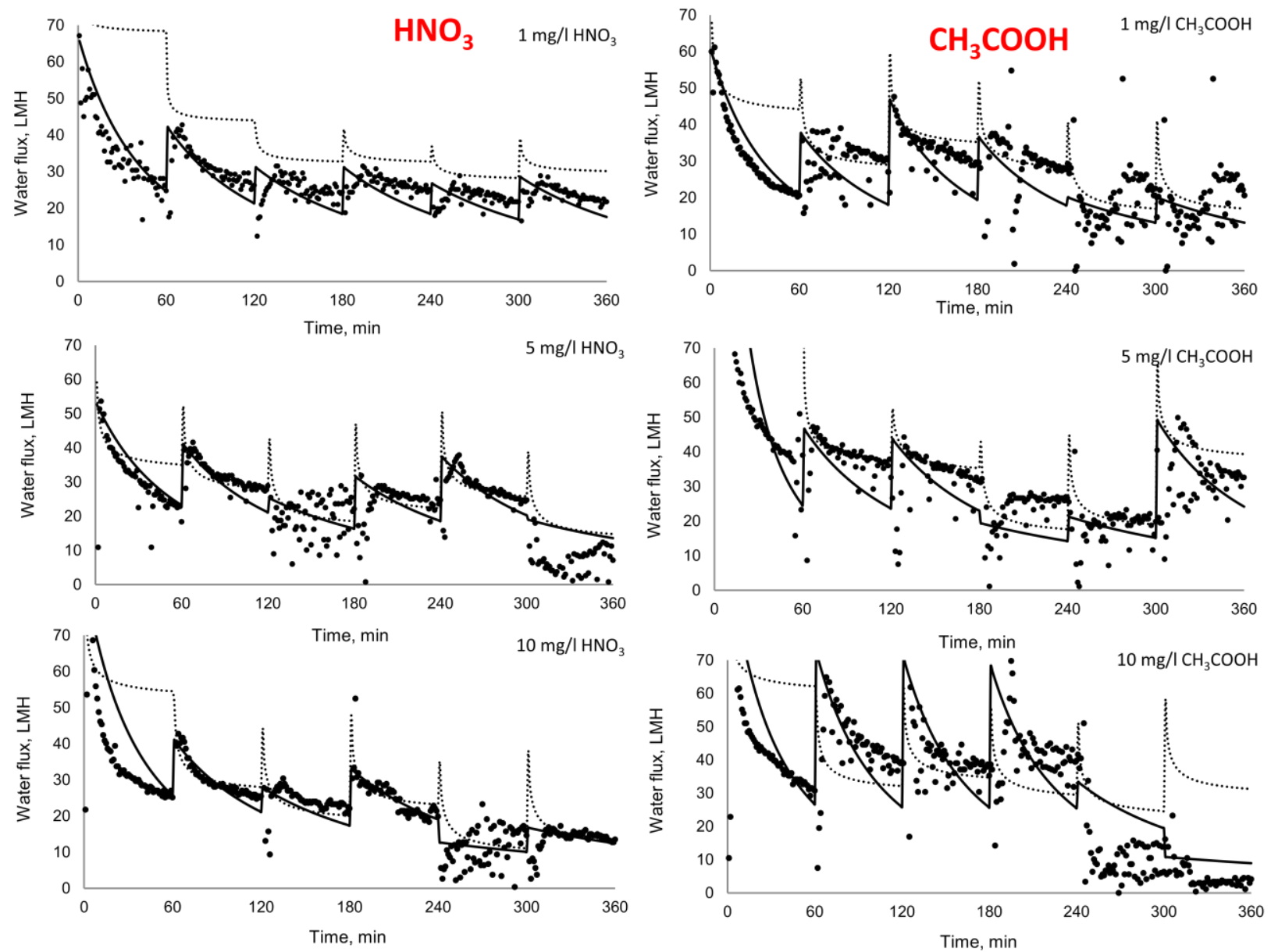

Figure 4. Evolution of flux as a function of filtration time through PES-300. Fouling with 0.6 g/L Similac 1 baby formula, cleaning with 5 (top), 25 (middle), and 50 (bottom) $\mathrm{mg} \cdot \mathrm{min} / \mathrm{L} \mathrm{HNO}_{3}$ (left), and with 5 (top), 25 (middle), and 50 (bottom) $\mathrm{mg} \cdot \mathrm{min} / \mathrm{L} \mathrm{CH}_{3} \mathrm{COOH}$ (right). Experimental data points are displayed as unconnected dots, a dashed curve is the best-fit approximation of flux behaviour due to cake formation, and a solid curve is a best-fit approximation of flux behaviour due to pore blocking (Equations (2) and (4), respectively). Here, $R_{M}$ is $1.1 \cdot 10^{13} \mathrm{~m}^{-1}$, TMP is $1.9 \cdot 10^{5} \mathrm{~Pa}, \alpha$ is $4.5-6.5 \cdot 10^{5} \mathrm{~m}^{-4}$, 

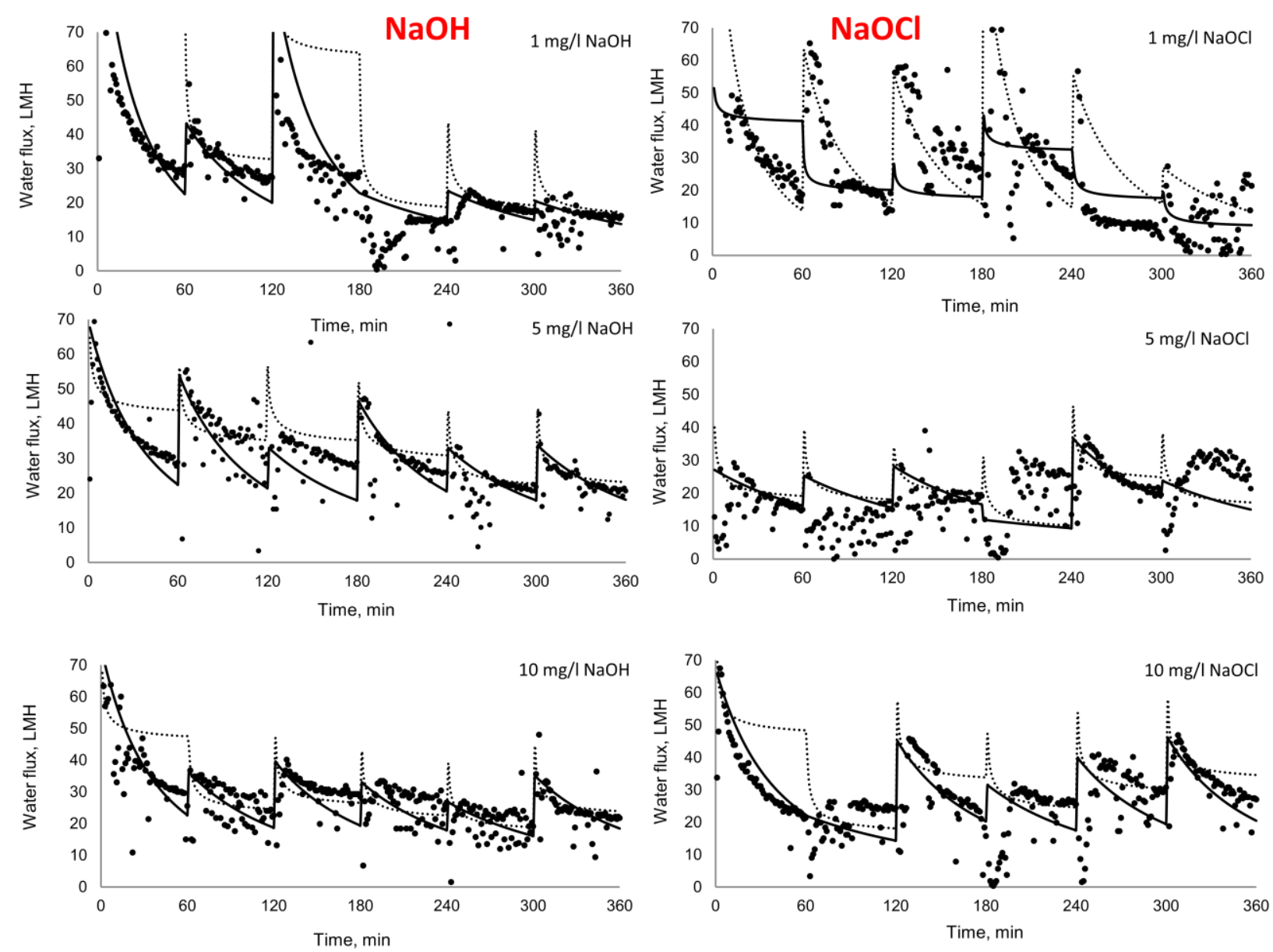

Figure 5. Evolution of flux as a function of filtration time through PES-300. Fouling with 0.6 g/L Similac 1 baby formula, cleaning with 5 (top), 25 (middle), and 50 (bottom) $\mathrm{mg} \cdot \mathrm{min} / \mathrm{L} \mathrm{NaOH}$ (left), and with 5 (top), 25 (middle), and 50 (bottom) $\mathrm{mg} \cdot \mathrm{min} / \mathrm{L} \mathrm{NaOCl}$ (right). Experimental data points are displayed as unconnected dots, a dashed curve is the best-fit approximation of flux behaviour due to cake formation, and a solid curve is a best-fit approximation of flux behaviour due to pore blocking (Equations (2) and (4), respectively). Here, $R_{M}$ is $1.1 \cdot 10^{13} \mathrm{~m}^{-1}$, TMP is $1.9 \cdot 10^{5} \mathrm{~Pa}, \alpha$ is $4.5-6.5 \cdot 10^{5} \mathrm{~m}^{-4}$, $\beta$ is $1.4-2.5 \cdot 10^{-10}, \lambda$ is $10^{-7} \mathrm{~m}$, and $\mu$ is $10^{-3} \mathrm{~kg} / \mathrm{m} \cdot \mathrm{s}$.

All plots showed a significant drop in the transmembrane flux, from 70 to less than $30 \mathrm{LMH}$, during the fouling of pristine membranes. The first cleaning successfully increased the flux to the 40-50 LMH domain for all three $\mathrm{Ct}$ values. From here, the flux after $\mathrm{HNO}_{3}$ cleaning gradually decreased towards $25 \mathrm{LMH}$ at the end of the second filtration period. The second cleaning was much less successful and did not increase flux above $30 \mathrm{LMH}$. High concentrations of the cleaning agents were more destructive, and after four consecutive cleans, the flux through membranes cleaned with 5 and $10 \mathrm{mg} / \mathrm{L}$ 
while providing consistent and repeatable runs. Similar trends were observed when cleaning with low concentrations of $\mathrm{CH}_{3} \mathrm{COOH}$. A gradual decrease in flux resulted in low flux after five to six cycles that required a change in the cleaning regime or membrane replacement. Cleaning with a high concentration of $\mathrm{CH}_{3} \mathrm{COOH}$ was successful for the first four cycles. After that, the flux simply dropped towards zero and was not recovered by cleaning.

The same pattern was observed when membrane was cleaned at low $\mathrm{NaOH}$ concentrations. After three cleaning cycles with $5 \mathrm{mg} / \mathrm{L} \cdot \min$ the flux diminished towards $0 \mathrm{LMH}$ and was restored after cleaning to a stable $15 \mathrm{LMH}$ level. Repeatable, although deteriorating, fouling patterns were observed when the membrane was cleaned with $25 \mathrm{mg} / \mathrm{L} \cdot \operatorname{min~} \mathrm{NaOH}$. After six cycles, flux dropped from 70 to $20 \mathrm{LMH}$ and produced a stable fouling pattern. The flux after cleaning with $5 \mathrm{mg} / \mathrm{L} \mathrm{NaOH}$ exhibited a trend that was not as repeatable as that at previous concentrations, i.e. the initial flux of $70 \mathrm{LMH}$ rapidly reduced towards $20 \mathrm{LMH}$ and remained stable after cycling.

The first clean with $\mathrm{NaOCl}$ restored the flux towards 65, 25, and $25 \mathrm{LMH}$ for $C t$ values of 5, 25, and $50 \mathrm{mg} \cdot \mathrm{min} / \mathrm{L}$, respectively. Cleaning with $1 \mathrm{mg} / \mathrm{L} \mathrm{NaOCl}$ resulted in a sporadic flux pattern when immediately after cleaning, flux increased to $60 \mathrm{LMH}$ although it ultimately reduced to 10-20 LMH towards the next clean. Following the fourth clean, the initial flux was unable to increase above 30 LMH and fluctuated significantly between 10 and $30 \mathrm{LMH}$. The fifth clean indicated that the membrane had completely fouled, and would not be able to operate any further using the same cleaning protocol. Cleaning with $5 \mathrm{mg} / \mathrm{L} \mathrm{NaOCl}$ resulted in a scattered flux pattern that fluctuated between 30-35 LMH immediately after cleaning and was practically zero LMH at the end of the filtration period. Cleaning with $10 \mathrm{mg} / \mathrm{L} \mathrm{NaOCl}$ produced a well-defined pattern of flux reductions towards 20 LMH immediately prior to cleaning, and flux increased toward 45 LMH immediately after the clean. The interim conclusion is that a 5 min cleaning with 5 or $10 \mathrm{mg} / \mathrm{L} \mathrm{NaOH}$ or $\mathrm{NaOCl}$ is sufficient to secure continuous filtration. Cleaning with $10 \mathrm{mg} / \mathrm{L}$ appears preferable as it provides a more consistent flux pattern with higher flux values. The flux after cleaning with $5 \mathrm{mg} / \mathrm{L} \mathrm{NaOCl}$ was observed to be chaotic and may increase the risk of further invasion of the membrane surface by foulants.

Flux patterns demonstrated a gradual transition from pore blocking to cake formation as filtration progressed. The first cycle displayed a significant flux decrease that fitted well with the anticipated reduction due to pore blocking. Two different paths were observed from the second sequence onwards. If chemical cleaning was successful, and the filtration path was restored, a flux pattern gradually 
evolved from pore blocking to cake formation. The initial flux values of the second run were comparable to each consecutive run, although the pattern was flatter and a better fit to the cake approximation was seen clearly. The absence of a gradual transition to cake fouling indicates that the membrane is continuously fouled and flux reduces till it becomes zero. Residual foulants assist in the densification of a fouling layer from new foulants. Sufficient chemical cleaning removes the residual foulants, exposing the membrane surface to new foulants. This trend was observed with ATR-FTIR, AFM, and contact angle measurements.

Figure 6 presents the AFM micrographs of pristine, fouled, and cleaned PES-300.
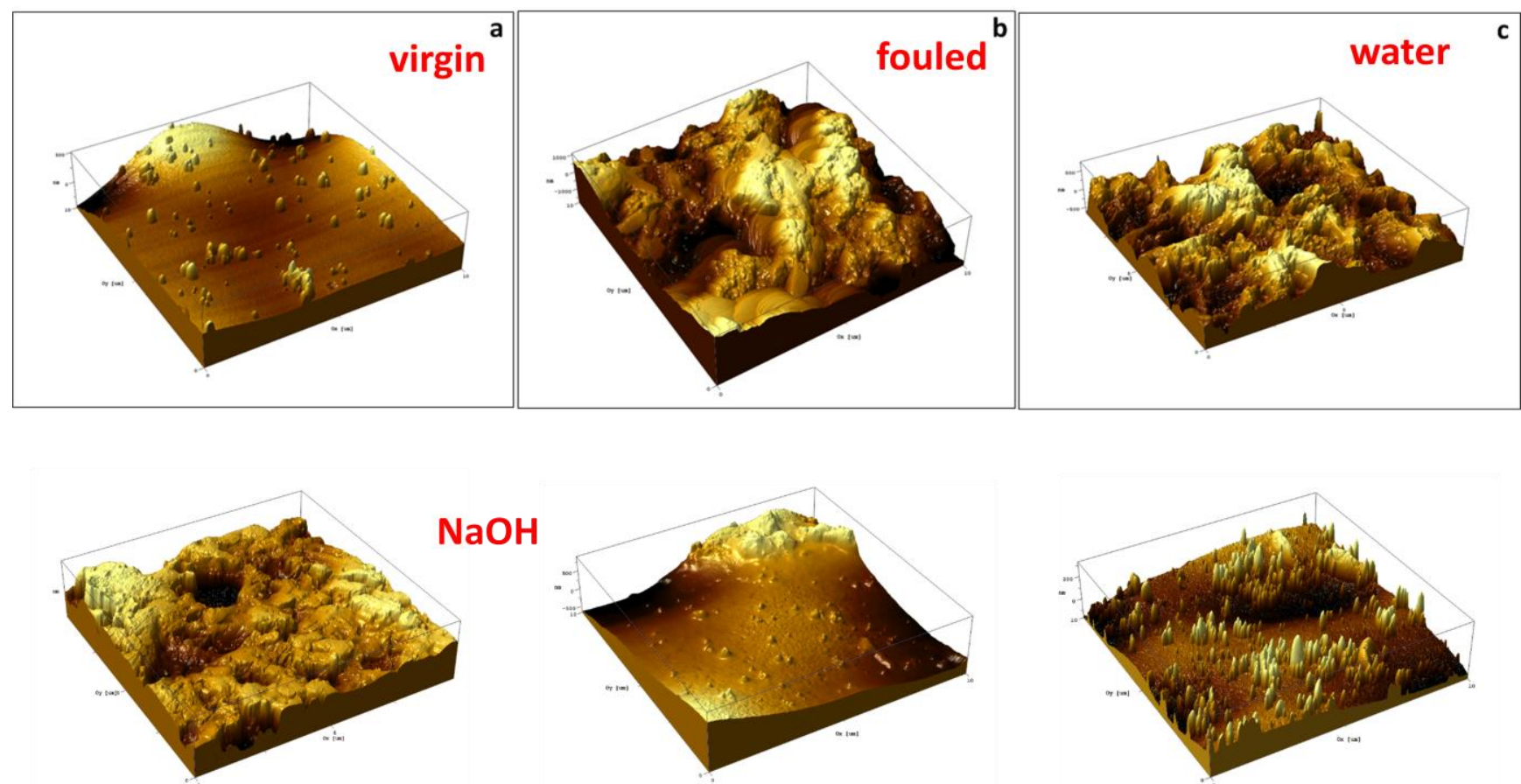

$\mathrm{NaOCl}$
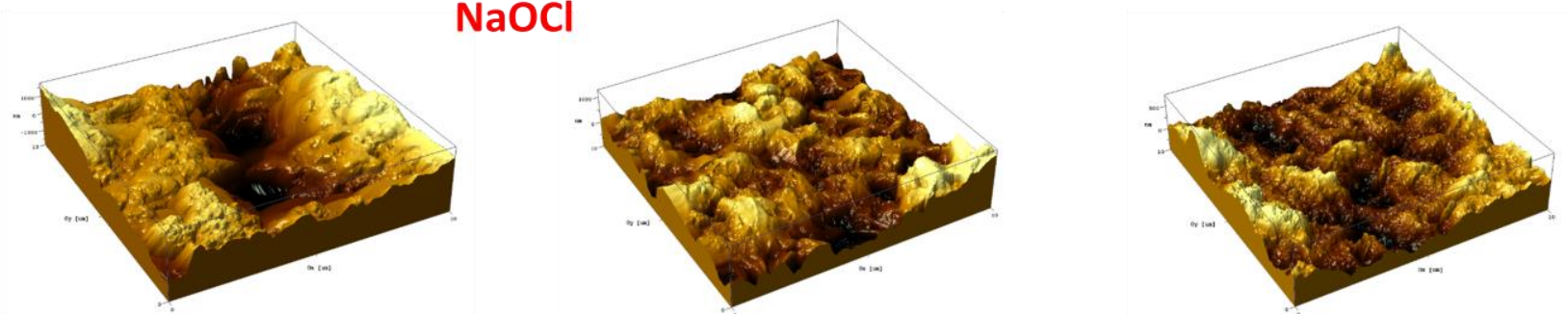

Figure 6. AFM of pristine (top left), fouled (top middle), and water-cleaned (top right) PES-300.

The middle row contains micrographs of the membrane cleaned with 1 (middle left), 5 (centre), and 10 (middle right) $\mathrm{mg} / \mathrm{L} \mathrm{NaOH}$. The bottom row is the PES-300 cleaned with 1 (bottom left), 5 (bottom middle), and 10 (bottom right) $\mathrm{mg} / \mathrm{L} \mathrm{NaOCl}$. 
As expected, the pristine membrane had the smoothest top layer [34,35]. The roughness of a fouled membrane is $1 \mu \mathrm{m}$; this is $400 \mathrm{~nm}$ thicker than the roughness of the pristine membrane. The higher roughness was evident through the larger differences between the bright and dark surface regions, indicating the highest membrane surface points and membrane pores. Hydraulic cleaning with water restored the roughness to $600 \mathrm{~nm}$ and left patches of fouling materials on the membrane surface. The most effective cleaning agent in terms of membrane roughness was chemical cleaning with $10 \mathrm{mg} / \mathrm{L}$ $\mathrm{NaOCl}$. The roughness of the fouling layer was $500 \mathrm{~nm}$; this is lower than the roughness of the pristine membrane. Roughness gradually decreased from $1000 \mathrm{~nm}$ after cleaning with $1 \mathrm{mg} / \mathrm{L} \mathrm{NaOCl}$, to 800 $\mathrm{nm}$ with $5 \mathrm{mg} / \mathrm{L} \mathrm{NaOCl}$, to $500 \mathrm{~nm}$ with $10 \mathrm{mg} / \mathrm{L} \mathrm{NaOCl}$. After all three cleans, the membrane surface remained replete with foulant residues. According to AFM, $\mathrm{NaOCl}$ cleaning agents concurrently attack the foulants and the membrane. The results of the attack are a partial destruction of the organics and a modified membrane surface. Complete destruction of proteins is achieved with $\mathrm{NaOH}$, resulting in a smooth surface with few remaining residuals.

Figure 7 illustrates the changes in the contact angle values of the pristine, fouled, and cleaned membranes as a function of the cleaning agent concentration.

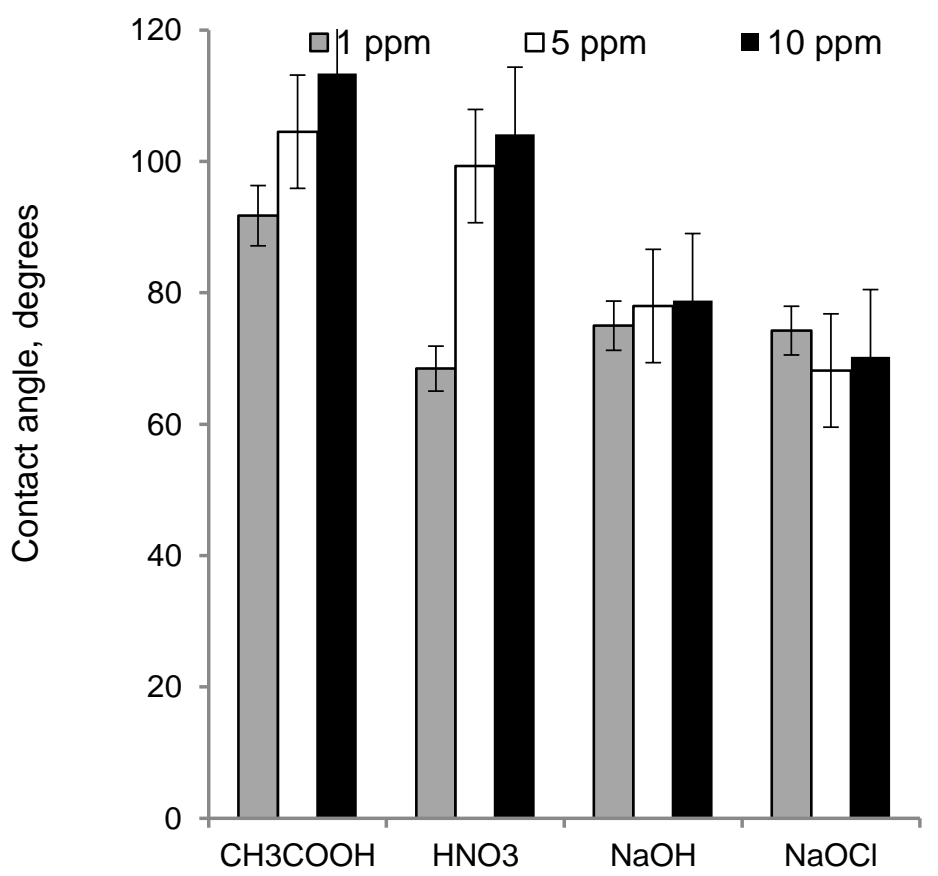

Figure 7. Contact angle of virgin, fouled, and cleaned membranes.

The lowest contact angle of $68^{\circ} \pm 3^{\circ}$ was observed for the pristine membranes, while fouling significantly increased the contact angle to $83^{\circ} \pm 4^{\circ}$. Hydraulic cleaning with water further increased the 
contact angle to $100^{\circ} \pm 5^{\circ}$. Cleaning with $\mathrm{CH}_{3} \mathrm{COOH}$ and $\mathrm{HNO}_{3}$ was unsuccessful; there were higher contact angles of up to $113^{\circ} \pm 4^{\circ}$ and $104^{\circ} \pm 3^{\circ}$ for $\mathrm{CH}_{3} \mathrm{COOH}$ and $\mathrm{HNO}_{3}$, respectively, at the highest cleaning doses. This suggests that acidic cleaning is not an appropriate approach for the removal of organic foulants. For $\mathrm{NaOH}$, cleaning with $1 \mathrm{mg} / \mathrm{L}$ resulted in a contact angle of $75^{\circ} \pm 3^{\circ}$; this is slightly higher than the contact angle of the pristine membrane. A $78^{\circ} \pm 3^{\circ}$ contact angle was observed in the membrane cleaned with 5 and $10 \mathrm{mg} / \mathrm{L} \mathrm{NaOH}$. NaOH efficiently lysed the foulant polymers [36] and resulted in their complete removal from the membrane surface. Almost completely bare membrane surfaces after $\mathrm{NaOH}$ cleaning were observed in the relevant AFM micrographs. A similar trend was observed in the cleaning of fouled membranes with $\mathrm{NaOCl}$. Cleaning with $1 \mathrm{mg} / \mathrm{L} \mathrm{NaOCl}$ resulted in a contact angle value of $74^{\circ} \pm 3^{\circ}$, which is slightly higher than that of the pristine membrane; contact angles of $68^{\circ} \pm 3^{\circ}$ and $70^{\circ} \pm 3^{\circ}$, respectively, were observed when the $\mathrm{NaOCl}$ concentrations were 5 and $10 \mathrm{mg} / \mathrm{L}$. The difference between the contact angles for these membranes and the pristine membrane is statistically insignificant and suggests that membranes were cleaned efficiently. Based on the observed trends, the most successful cleans were conducted with $\mathrm{NaOH}$ and $\mathrm{NaOCl}$. Relatively minor differences in the observed contact angle values do not permit the formulation of specific recommendations.

Previous studies on fouled membranes have not focussed on changes in the contact angle values. In addition, contact angle measurements were routinely conducted and reported as a part of a comprehensive characterisation of pristine and fouled membranes. Changes in contact angle values as a function of fouling matter, the thickness, and charge [37] were counterbalanced by changes in membrane roughness [38] measured with AFM. It is difficult to determine the exact reason that leads to changes in the contact angle values; it is easy to correlate these changes with membrane roughness. Thoroughly cleaned smooth surfaces display values that are similar to the values for the pristine membrane; this represents the characteristics of the membrane material. Insufficiently cleaned membrane surfaces are rough and display contact angle values significantly higher than those of the pristine membrane.

The chemical cleanliness of the membrane surface was examined using ATR-FTIR. The results are presented in Figures 8 and 9. 

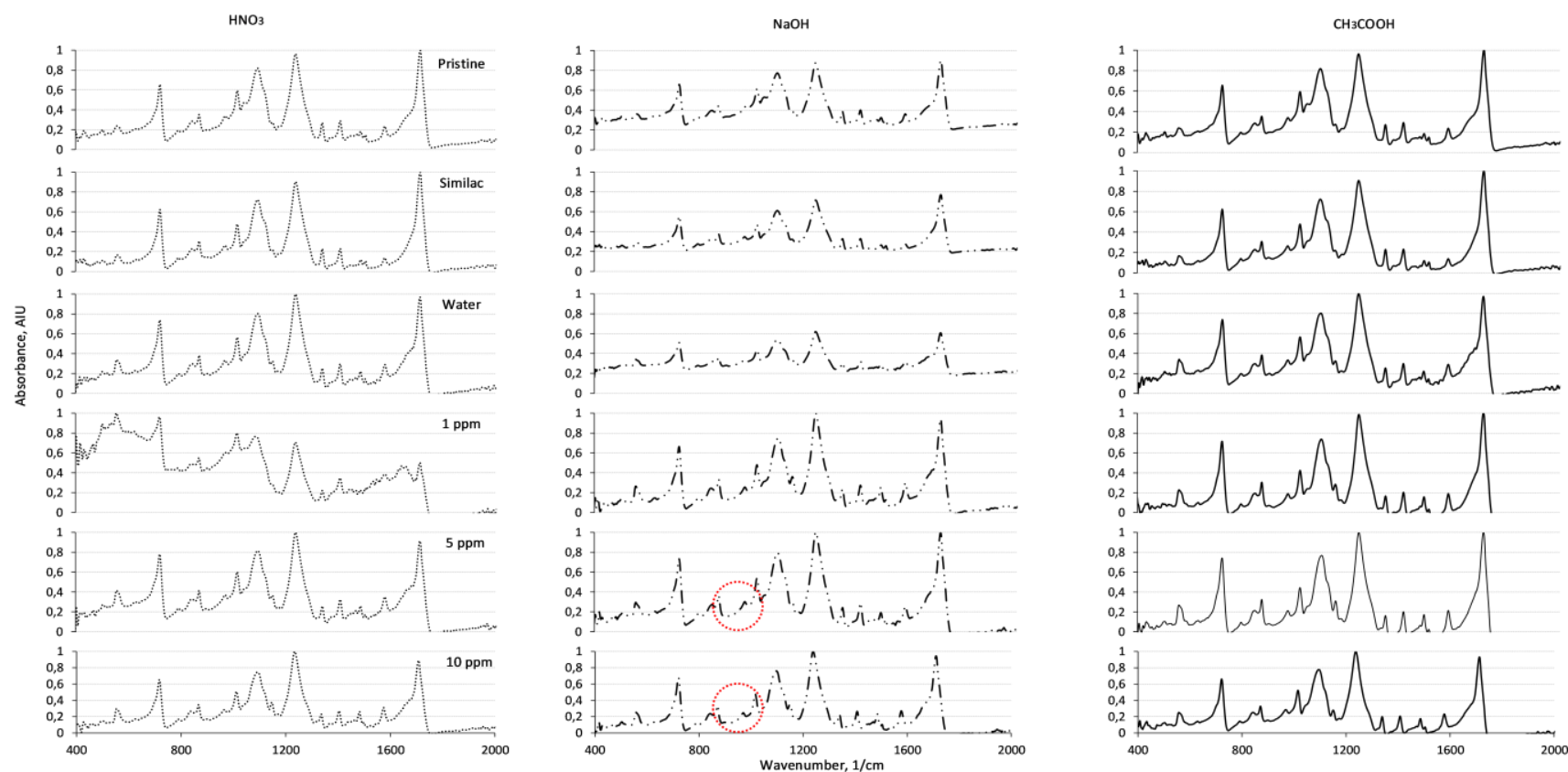

Figure 8. ATR-FTIR spectra of pristine, fouled, and cleaned PES-300 membrane. The spectra set after $\mathrm{HNO}_{3}$ (left), $\mathrm{NaOH}$ (middle), and $\mathrm{CH}_{3} \mathrm{COOH}$ (right) cleanings show the pristine (top), Similacbottom), $5 \mathrm{mg} / \mathrm{L}$ (second bottom, and $10 \mathrm{mg} / \mathrm{L}$ (bottom) cleaning agent PES-300 membrane. 

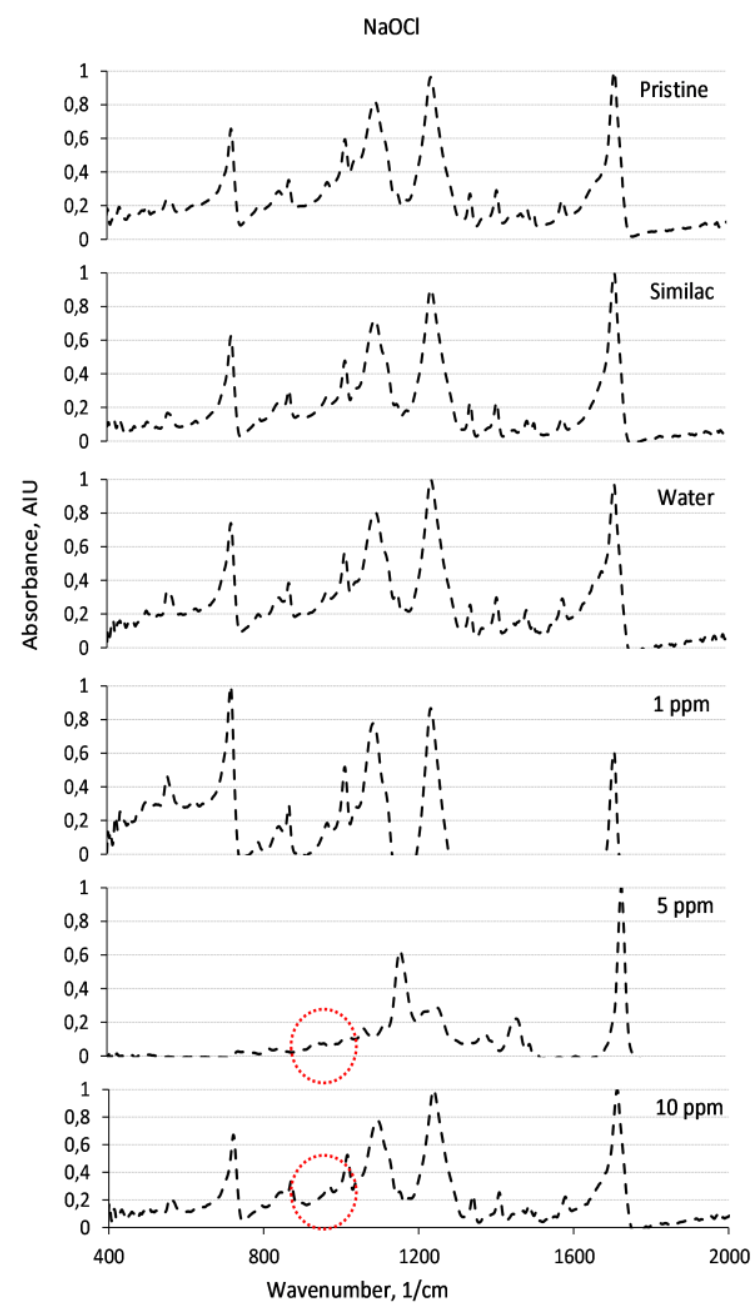

Figure 9. ATR-FTIR spectra of pristine, fouled, and NaOCl-cleaned PES-300 membrane. The set shows ATR-FTIR spectra of pristine (top), Similac-fouled (second top), fouled and water-cleaned (third top), fouled and cleaned with $1 \mathrm{mg} / \mathrm{L}$ (third bottom), $5 \mathrm{mg} / \mathrm{L}$ (second bottom, and $10 \mathrm{mg} / \mathrm{L}$

All samples showed a very broad band in the infrared (IR) range of 3300-3400 $\mathrm{cm}^{-1}$ (not shown in figure) typically associated with $\mathrm{O}-\mathrm{H}$ vibrations in water and carbohydrate-like organic matter [39]. Other peaks associated with a pristine PES membrane reflected its structure consisting of a benzene ring, a sulfone group, and an ether bond [40]. Table 1 presents the IR absorption bands relevant to the PES structure.

Table 1. Assignment of relevant IR absorption bands to PES-300.

$\begin{array}{lll}\text { IR band, } \mathrm{cm}^{-1} & \begin{array}{l}\text { Range given in the } \\ \text { literature [49], } \mathrm{cm}^{-1}\end{array} & \text { Assignment }\end{array}$

555, 620, 915, $\quad 1000 \leq \quad$ Benzene rings




\begin{tabular}{|c|c|c|}
\hline $942,990,1$ & & \\
\hline 1030 & About 1030 & Benzene ring \\
\hline 1100 & $1085-1125$ & C-O stretching vibration \\
\hline 1150 & 1150 up to 1225 & $\begin{array}{l}\text { O-H deformation and } \mathrm{C}-\mathrm{O} \text { stretching } \\
\text { vibration interaction }\end{array}$ \\
\hline 1250 & $1275-1200$ & \\
\hline 1290 & $1300-1050$ & R-C-O-C-R \\
\hline 1320 & $1310-1350$ & \\
\hline 1485 & $1460-1550$ & $\mathrm{C}-\mathrm{S}$ \\
\hline 1575 & About 1580 & Aromatic systems \\
\hline 1650 & 1580 up to 1660 & $\mathrm{C}=\mathrm{C}$ stretching vibration \\
\hline
\end{tabular}

Usually, peaks at $1240 \mathrm{~cm}^{-1}$ are ascribed to aromatic ethers and sulfonyl groups of PES. The peak at $1650 \mathrm{~cm}^{-1}$ corresponds to the $\mathrm{C}=\mathrm{C}$ stretching vibration. The band at $717 \mathrm{~cm}^{-1}$ is due to the $\mathrm{C}-\mathrm{S}$ groups; the bands at 1375 and $1109 \mathrm{~cm}^{-1}$ are attributable to the sulfone group, while the $1460-1470 \mathrm{~cm}^{-1}$ band is indicative of alkanes [41]. The IR spectral data of proteins consist of nine characteristic absorption bands of amides A, B, and I-VII. Table 2 presents the IR absorption bands of the proteins.

Table 2. Characteristics IR bands of proteins.

\begin{tabular}{ccc} 
IR band, $\mathrm{cm}^{-1}$ & Designation & Description \\
\hline 200 & Amide VII & Skeletal torsion \\
$537-606$ & Amide VI & Out-of-plane C=O bending \\
$625-767$ & Amide IV & OCN bending \\
$640-800$ & Amide V & Out-of-plane NH bending \\
$1229-1301$ & Amide III & CN stretching, NH bending \\
$1480-1575$ & Amide II & CN stretching, NH bending \\
$1600-1690$ & Amide I & C=O stretching \\
3100 & Amide B & NH stretching \\
3300 & Amide A & NH stretching \\
\hline
\end{tabular}

The protein fingerprints on the membrane surface may only be found if there is a lack of PES absorption bands in the desired IR range. Unfortunately, the amide II area of proteins (C-N and N-H bonds) overlapped with a strong peak at $1575 \mathrm{~cm}^{-1}$ assigned to the PES aromatic bond (Table 1). The amide I (carbonyl $\mathrm{C}=\mathrm{O}$ bond) overlapped with the $\mathrm{C}=\mathrm{C}$ stretching vibration band at $1650 \mathrm{~cm}^{-1}$. The clearly observed trends are the disappearance of a band at $2270-2340 \mathrm{~cm}^{-1}$ (not shown in figure), 
which corresponds to the $\mathrm{N}=\mathrm{C}=\mathrm{O}$ isocyanate group or $\mathrm{C}=\mathrm{N}=\mathrm{O}$ asymmetric stretch vibration. The band was clearly observable in the virgin and Similac-fouled samples and disappeared after cleaning. The band is attributed to polyvinylpyrrolidone (PVP), a preservative used to fill pores in the UF membranes and create more hydrophilic membranes. The PVP was washed out during cleaning, leaving a more hydrophobic membrane [42]. Another peak that had completely disappeared after cleaning was located at $3400 \mathrm{~cm}^{-1}$ (not shown in figure), and was also attributed to organic preservatives. Another band that appears in the virgin PES then disappears after fouling or cleaning was located at $1070 \mathrm{~cm}^{-1}$. This peak was attributed to $\mathrm{O}=\mathrm{S}=\mathrm{O}$ symmetric stretching [43,44]. Its gradual disappearance indicates a possible chain scission of ether sulfone and the formation of phenyl sulfonate. The mechanism of chain scission is usually explained by the deprotonation of $-\mathrm{CH}_{2}$, followed by the formation of $\mathrm{C}=\mathrm{C}$ double bonds [14].

The contact angle, AFM, and ATR-FTIR provide important information regarding the efficiency of chemical cleaning, although dismantling of a module is required for off-situ analysis. In the absence of any solid reason, these methods will not be applied for a routine check of cleaning efficiency. This leaves the evaluation of flux fluctuations. The surface properties of a membrane were not evaluated, although they may be affected by cleaning. Zeta potential measurements provide additional useful information on the surface state of the membrane. Figure 10 presents the zeta potential values of the pristine, fouled, and cleaned membranes. 

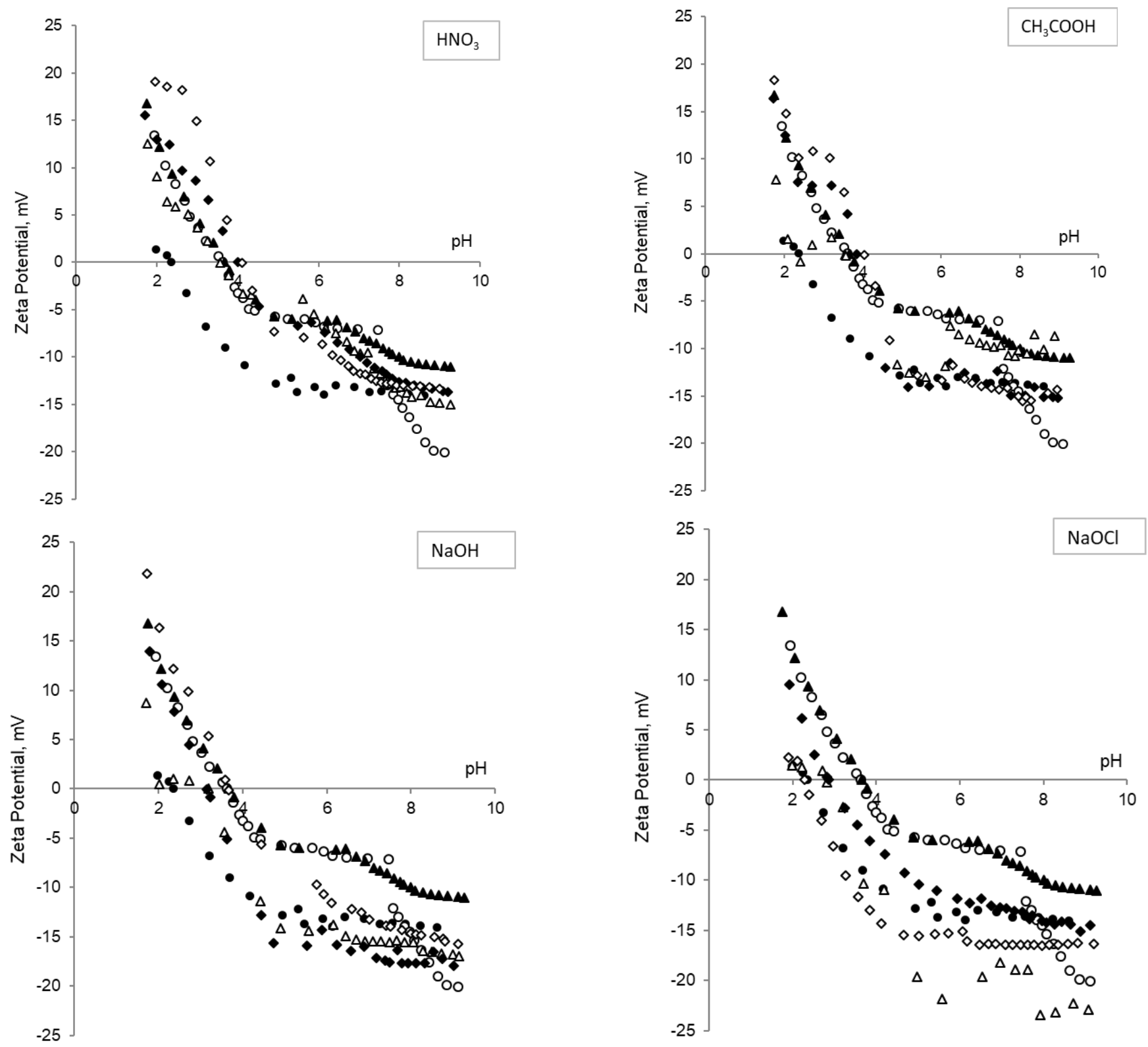

Figure 10. Zeta potential values of pristine (black circles), fouled (hollow circles), water-washed (black triangles), and cleaned with 1 (hollow triangles), 5 (black diamonds), and 10 (hollow diamonds) $\mathrm{mg} / \mathrm{L}$ of $\mathrm{HNO}_{3}$ (top left), $\mathrm{CH}_{3} \mathrm{COOH}$ (top right), $\mathrm{NaOH}$ (bottom left), and $\mathrm{NaOCl}$ (bottom right) cleaning solution PES-300 membrane; the membrane was fouled with $0.6 \mathrm{~g} / \mathrm{L}$ Similac 1 baby formula.

The zeta potential of the pristine membrane displayed slightly positive values at $\mathrm{pH} 2$, had a point of zero charge (pzc) at $\mathrm{pH} 2.36$, became increasingly negative until $\mathrm{pH} 6$, and had a plateau at a $\mathrm{pH}$ higher than 6. The fouled membrane displayed a greater number of positive values, had a pzc at $\mathrm{pH}$ 3.6, maintained negative values of $-5 \mathrm{mV}$ until $\mathrm{pH} \mathrm{7,} \mathrm{and} \mathrm{became} \mathrm{increasingly} \mathrm{negative} \mathrm{until}-20 \mathrm{mV}$ at 
surface [45]. Fouled membranes cleaned with water had zeta potential values similar to those of the fouled membrane until $\mathrm{pH} \mathrm{7,} \mathrm{and} \mathrm{slightly} \mathrm{increased} \mathrm{negative} \mathrm{values} \mathrm{towards}-11 \mathrm{mV}$ at $\mathrm{pH}$ 9.3. Cleaning with $1 \mathrm{mg} / \mathrm{L} \mathrm{HNO}_{3}$ for 5 min resulted in a positive shift of zeta potential values, pzc at $\mathrm{pH}$ 3.57, and a slow decline of zeta potential values toward a plateau at $-15 \mathrm{mV}$ at $\mathrm{pH} \sim 9$. Similar trends with minor changes were observed in the zeta potential values for the membrane cleaned with 5 and 10 $\mathrm{mg} / \mathrm{L} \mathrm{HNO}_{3}$. The trends closely resembled the values for cleaning with water with the exception of a greater number of negative values at $\mathrm{pH}>6$. The zeta potential values of PES-300 cleaned with $\mathrm{CH}_{3} \mathrm{COOH}$ were different from those observed for the pristine membrane although they were close to each other and to the zeta potential values of $\mathrm{HNO}_{3}$; the difference appeared in the positive values largely found at higher acid doses. The cleaning resulted in 8,16 , and $18 \mathrm{mV}$ at $\mathrm{pH} 1.7$ for a fouled membrane cleaned with 1,5 , and $10 \mathrm{mg} / \mathrm{L} \mathrm{CH}_{3} \mathrm{COOH}$, respectively. These values rapidly decreased to zero in the pzc of all three curves at $\mathrm{pH} 3.85,4$, and 4.1 for the same cleaning sequence. The zeta potential of the membrane cleaned with $1 \mathrm{mg} / \mathrm{L} \mathrm{CH} 3 \mathrm{COOH}$ became close to the values obtained after cleaning the membrane with water. Cleaning with 5 and $10 \mathrm{mg} / \mathrm{L} \mathrm{CH}_{3} \mathrm{COOH}$ resulted in zeta potential values similar to that of the pristine membrane at $\mathrm{pH}>6$. Cleaning with $\mathrm{NaOH}$ resulted in more positive zeta potential values at low $\mathrm{pH}$, pzc at $\mathrm{pH} 3.2$ for 1 and $5 \mathrm{mg} / \mathrm{L} \mathrm{NaOH}$, pzc at $\mathrm{pH} 3.6$ for cleaning with $10 \mathrm{mg} / \mathrm{L} \mathrm{NaOH}$, and more negative values for the cleaned membrane at $\mathrm{pH}>7$. The zeta potential values of the pristine membrane were around $-12 \mathrm{mV}$, and those of the membranes cleaned with $\mathrm{NaOH}$ at all three concentrations were approximately $-17 \mathrm{mV}$ for $\mathrm{pH}>6$. A plateau in zeta potential values was observed for the pristine as well as the $\mathrm{NaOH}$-cleaned membranes, indicating the adsorption equilibrium between the membrane surface and the bulk at a $\mathrm{pH}$ range [46]. The zeta potential values observed after cleaning with $\mathrm{NaOCl}$ were very similar to the values of the pristine membrane. The pzc of the pristine membrane was at $\mathrm{pH} 2.4$. and the pzc for the cleaned membranes was at $\mathrm{pH}$ 2.3-2.9. The values for the membrane cleaned with $1 \mathrm{mg} / \mathrm{L} \mathrm{NaOCl}$ became more or less trendy with the values of the pristine membrane. The values for the membrane cleaned with $10 \mathrm{mg} / \mathrm{L}$ $\mathrm{NaOCl}$ were slightly more negative and displayed a plateau at $-16 \mathrm{mV}$, and the values for the membrane cleaned with $5 \mathrm{mg} / \mathrm{L} \mathrm{NaOCl}$ were almost identical to those observed for the pristine membrane.

Figure 11 depicts the cleaning efficiency assessed by the relative flux dissimilarity. 

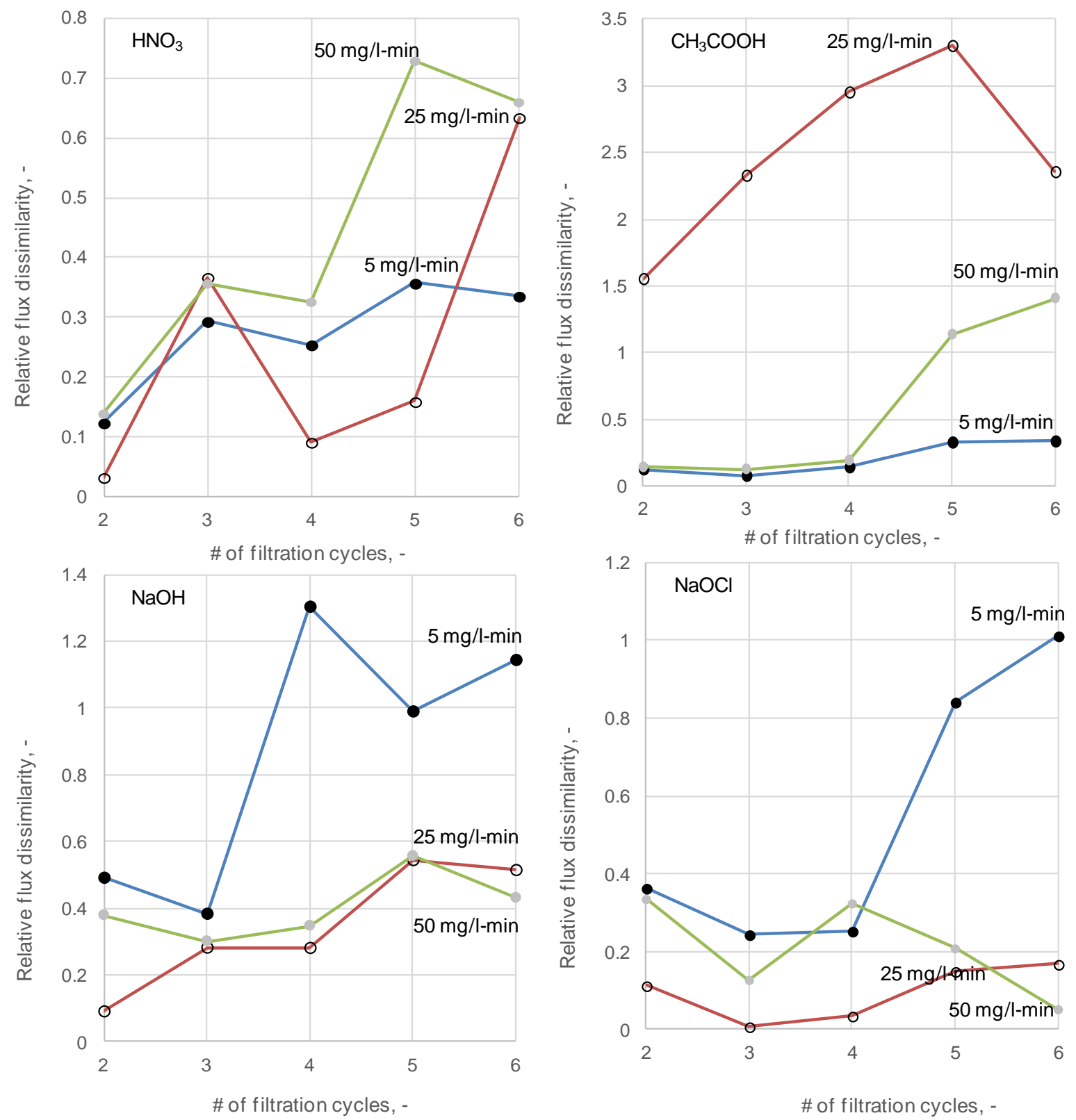

Figure 11. The efficiency of chemical cleaning assessed by the relative similarity in flux values of pristine, fouled, and cleaned membranes.

The fouling pattern at each run was compared to the fouling pattern during the first run conducted with the virgin membrane, and normalised by comparing the first run to a DIW run at $70 \mathrm{LMH}$. Efficient cleaning should result in the exact same fouling pattern for each consecutive run with low dissimilarity between runs. The relative dissimilarity in fluxes at the initial two runs was always approximately $0.3-$ 0.4 , meaning that the flow patterns differed by approximately $30-40 \%$. After that, the dissimilarity shows various trends. Cleaning with $\mathrm{HNO}_{3}$ resulted in a constant dissimilarity pattern at $5 \mathrm{mg} / \mathrm{L} \cdot \mathrm{min}$, and increased dissimilarity was observed at 25 and $50 \mathrm{mg} / \mathrm{L} \cdot \mathrm{min}$. According to the flux pattern, 
although cleaning with $\mathrm{HNO}_{3}$ may be conducted at $5 \mathrm{mg} / \mathrm{L} \cdot \mathrm{min}$, this is not the case at 25 or 50 mg/L.min. The two latter concentrations produced a flux that was significantly different from the initial fouling flux. An increasing relative dissimilarity suggests that the flux reduces toward negligible values; as such, cleaning with high concentrations of $\mathrm{HNO}_{3}$ is not advisable.

A similar conclusion was drawn when a fouled membrane was cleaned with $\mathrm{CH}_{3} \mathrm{COOH}$. A relative dissimilarity value of up to 3.5 suggests that the only usable concentration of the cleaning agent was 5 $\mathrm{mg} / \mathrm{L} \mathrm{CH} \mathrm{CH}_{3} \mathrm{COOH}$. The opposite was observed when cleaning with $\mathrm{NaOH}$ and $\mathrm{NaOCl}$. Cleaning with low concentrations of the cleaning agent produced a significantly different pattern with up to twotimes the dissimilarity between the initial fouling flux pattern and a pattern observed after six runs. The relative dissimilarity in cleaning when using 25 and $50 \mathrm{mg} / \mathrm{L} \mathrm{NaOH}$ was approximately 0.5 , and with $\mathrm{NaOCl}$ it was below 0.2. Based on these observations, better results are expected with 25 and 50 $\mathrm{mg} / \mathrm{L} \cdot \mathrm{min} \mathrm{NaOCl}$. Other cleaning options that can be considered include 25 and $50 \mathrm{mg} / \mathrm{L} \cdot \mathrm{min} \mathrm{NaOH}$, and $25 \mathrm{mg} / \mathrm{L} \cdot \min \mathrm{HNO}_{3}$ and $\mathrm{CH}_{3} \mathrm{COOH}$. These are typical observations which have been previously reported. The cleaning of an UF membrane fouled by proteins with a liquid bleach is a classical application. However, the observed trends can be further tuned by observing trends in the relative dissimilarity of the zeta potential.

Figure 12 depicts the cleaning efficiency assessed by the relative dissimilarity of the zeta potential.

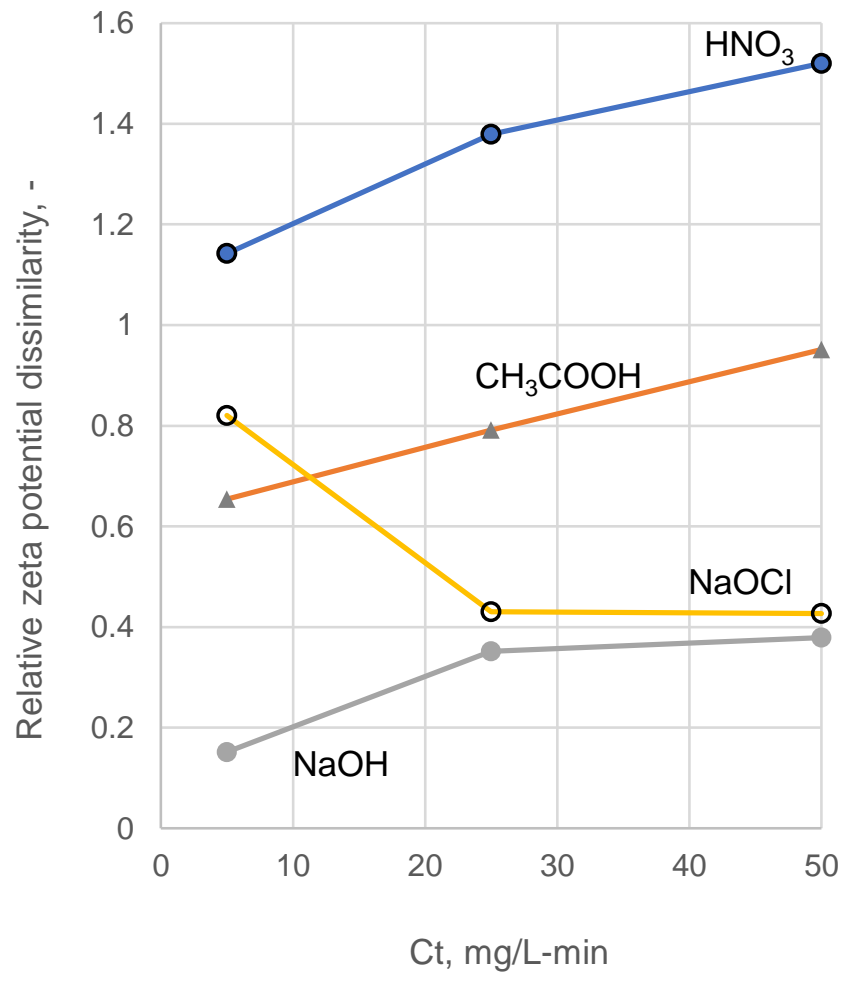


Figure 12. Cleaning efficiency as assessed by the dissimilarity in zeta potential values of the pristine and cleaned membranes.

The dissimilarity in zeta potential values was calculated by comparing the zeta potential values of the pristine and fouled-cleaned membranes at different $\mathrm{pH}$ levels. A higher difference in zeta potential values indicates that the membrane remains fouled after cleaning. Cleaning with $\mathrm{HNO}_{3}$ resulted in a high dissimilarity between the pristine and cleaned membranes. Moreover, a higher concentration of a cleaning agent increased this dissimilarity. A similar response was observed when the membrane was cleaned with $\mathrm{CH}_{3} \mathrm{COOH}$, although this dissimilarity was observed at a smaller scale. Zeta potential dissimilarities in the range of 0.6-1.5 indicate that the membrane has been completely fouled. Cleaning with $\mathrm{NaOH}$ was the most successful when its concentration was $5 \mathrm{mg} / \mathrm{L} \cdot \mathrm{min}$, although 25 and $50 \mathrm{mg} / \mathrm{L} \cdot \min \mathrm{NaOH}$ also resulted in membrane cleaning. While cleaning with $\mathrm{NaOCl}$ could be conducted with 25 and $50 \mathrm{mg} / \mathrm{L} \cdot \operatorname{min~} \mathrm{NaOCl}$, this was not the case with $5 \mathrm{mg} / \mathrm{L} \cdot \mathrm{min} \mathrm{NaOCl}$; the zeta potential difference was substantial. Combining the relative flux dissimilarity and zeta potential difference narrows the appropriate range of cleaning procedures. First, it eliminates the option of cleaning with $25 \mathrm{mg} / \mathrm{L} \cdot \min \mathrm{HNO}_{3}$ and $\mathrm{CH}_{3} \mathrm{COOH}$. Although the fouling pattern appears the same, the zeta potential difference highlights the significant fouling that may be detected in situ and in the early stages. The cleaning observed for 25 and $50 \mathrm{mg} / \mathrm{L} \cdot \mathrm{min} \mathrm{NaOH}$ and $\mathrm{NaOCl}$ was similar. Cleaning may be conducted with $25 \mathrm{mg} / \mathrm{L} \cdot \min$ of $\mathrm{NaOH}$ or $\mathrm{NaOCl}$, making the cleaning safer and more environmentally friendly.

\section{Discussion}

Chemical cleaning of the UF membranes is a part of daily membrane operation. Cleaning efficiency was assessed using hydraulic tests that evaluate flux before and after the cleaning and through numerous variations of the bubble point test. The latter is needed to ensure that cleaning did not affect membrane integrity up to the extent at which the membrane contains pores larger than $1 \mu \mathrm{m}$. This is critical for the effective disinfection by the UF membranes in terms of preventing the penetration of bacteria typically larger than $1 \mu \mathrm{m}$. However, two other previously defined cleaning criteria, chemical cleanliness (removal of all foulants, impurities, and residues of cleaning agents) and microbiological cleanliness (absence of living microorganisms), are not typically evaluated [47]. However, chemical cleaning is a complex interplay between foulants, cleaning agents, and membrane surfaces. This is especially important for UF with polymer membranes that may be affected by the type and concentration of the cleaning agent. Possible undesirable outcomes include insufficient cleaning that 
maintains foulants on the membrane surface, sufficient cleaning that disintegrates the foulants while preserving some organic matter on the membrane surface, and overcleaning that removes all foulants and also modifies the membrane surface. These outcomes cannot be assessed by current tests that are based on general knowledge and the monitoring of flux behaviour after cleaning; additional tests for fine tuning of chemical cleaning are required, and these should be non-invasive, inexpensive, and applicable in situ.

Membrane cleaning affects the permeability and zeta potential of polymer UF membranes. Zeta potential values of protein-fouled membrane shift towards more positive values, suggesting that organics are adsorbed on the membrane surface. The removal of organics by chemical cleaning changes the zeta potential values back to those of a virgin membrane. A parallel evaluation of the zeta potential with transmembrane flux can hint on one of three possible scenarios. When the zeta potential values of a cleaned membrane are more positive than those of a virgin membrane, and flux is lower than the flux through a pristine membrane, the membrane has been insufficiently cleaned although it is still intact. When both zeta potential and flux values are similar to those of a pristine membrane, the membrane is hydraulically and chemically clean, and remains intact. When the zeta potential values are similar or more electronegative than the values of a pristine membrane, and the transmembrane flux is higher than the flux through the pristine membrane, the membrane surface is altered. This alteration may take a form of increased hydrophilicity, higher surface charge, or damage to the membrane integrity. A pH-streaming potential profiling differentiates between regions where the streaming potential curve of a fouled-cleaned membrane is above the curve of the pristine membrane, close to it, or below it. Profiling also determines the preferable adsorption and cleaning zones. In our study, the highest adsorption of foulants and the lowest efficiency of cleaning agents was observed under acidic conditions. There was insufficient electrostatic repulsion between the two under neutral conditions, and thus the possible removal of foulants from the membrane surface was due to chemical disintegration. Effective removal under alkaline conditions was due to the combined effect of denaturation and the electrostatic repulsion of mutually negatively charged membrane and foulants [48].

Another especially valuable and relatively simple test is the modification of the KolmogorovSmirnov test for data dissimilarities collected through flux or zeta potential measurements. The typical approach is to compare the flux through a virgin membrane and a fouled-cleaned membrane. A higher ratio of the latter to the former indicates a more cleaned membrane, while also signifying a more modified membrane. The cleaning in this instance indicates a modification of the membrane surface in 
terms of the removal of preservatives, or an increase in the membrane hydrophilicity through the adjustment of membrane surface groups, or an enlargement of membrane pores. All these positive effects are short and result in more severe fouling. Instead, exactly same fouling pattern and minimal difference in streaming potential values of pristine and cleaned membranes indicate that the membrane performs in the exact same manner time after time. And that is exactly what the test does. It is able to compare the similarities in fouling patterns. The repetition of a pattern with minimal deviations suggests that the cleaning procedure is optimal and may be maintained for a long period. Significant deviations suggest that the cleaning procedure should be optimised. However, the flux measurements are not sufficiently sensitive and need to be supported by another test; this is where the zeta potential dissimilarity test comes into play. When the fouling dissimilarity pattern suggests multiple choices, the zeta potential highlights the most prominent options. In this case, cleaning with $25 \mathrm{mg} / \mathrm{L} \cdot \mathrm{min}$ of $\mathrm{NaOH}$ or $\mathrm{NaOCl}$ was found to be as efficient as cleaning with $50 \mathrm{mg} / \mathrm{L} \cdot \mathrm{min} \mathrm{NaOH}$ or $\mathrm{NaOCl}$. Applying half doses of cleaning agents is a more economical and environmentally friendly procedure.

\section{Conclusions}

- Parallel measurements of transmembrane flux and $\mathrm{pH}$-streaming potential profiling of pristine and chemically cleaned membranes are needed to develop site-specific cleaning protocols. The approach is easy to implement, does not require expensive equipment, may be conducted in situ, and may be expanded to address the efficiency of coagulation/flocculation. The expected benefits in implementing the proposed approach include reduced cleaning time, reduced concentration of cleaning agents, and an increased lifetime of the UF membranes.

- A modified Kolmogorov-Smirnov test for dissimilarities in data collected through flux or streaming potential measurements provides immediate, highly relevant statistical analysis to evaluate the efficiency of the cleaning procedure.

- Chemical cleaning of the fouled UF membranes may be tuned to address a specific composition of the feed and become a site-specific procedure.

\section{Funding sources}

This work was supported by Nazarbayev University (grant number 110119FD4533).

\section{References}

[1] I. Levitsky, Y. Dahan, E. Arkhangelsky, V. Gitis, Retention of modified BSA by ultrafiltration membranes, Journal of Chemical Technology and Biotechnology. 91 (2016) 400-407. https://doi.org/10.1002/jctb.4588. 
[2] E. Arkhangelsky, I. Levitsky, V. Gitis, Retention of Biopolymers by Ultrafiltration Membranes, Chemical Engineering and Technology. 38 (2015) 2327-2334. https://doi.org/10.1002/ceat.201400775.

[3] X. Shi, G. Tal, N.P. Hankins, V. Gitis, Fouling and cleaning of ultrafiltration membranes: A review, Journal of Water Process Engineering. 1 (2014) 121-138. https://doi.org/10.1016/j.jwpe.2014.04.003.

[4] Z. Wang, J. Ma, C.Y. Tang, K. Kimura, Q. Wang, X. Han, Membrane cleaning in membrane bioreactors: A review, Journal of Membrane Science. 468 (2014) 276-307. https://doi.org/10.1016/j.memsci.2014.05.060.

[5] I. Levitsky, A. Duek, E. Arkhangelsky, D. Pinchev, T. Kadoshian, H. Shetrit, R. Naim, V. Gitis, Understanding the oxidative cleaning of UF membranes, Journal of Membrane Science. 377 (2011) 206-213. https://doi.org/10.1016/j.memsci.2011.04.046.

[6] V. Gitis, R.C. Haught, R.M. Clark, J. Gun, O. Lev, Application of nanoscale probes for the evaluation of the integrity of ultrafiltration membranes, Journal of Membrane Science. 276 (2006) 185-192. https://doi.org/10.1016/j.memsci.2005.09.055.

[7] GE Healthcare, Cleaning of cross flow filtration membranes, Technical Brief 18-1171-72 AA, 2005.

[8] Q. Gan, J.A. Howell, R.W. Field, R. England, M.R. Bird, M.T. McKechinie, Synergetic cleaning procedure for a ceramic membrane fouled by beer micro®ltration, Journal of Membrane Science. 155 (1999) 277-289.

[9] M.A. Argüello, S. Álvarez, F.A. Riera, R. Álvarez, Utilization of enzymatic detergents to clean inorganic membranes fouled by whey proteins, Separation and Purification Technology. 41 (2005) 147-154. https://doi.org/10.1016/j.seppur.2004.05.005.

[10] P. Blanpain-Avet, J.F. Migdal, T. Bénézech, The effect of multiple fouling and cleaning cycles on a tubular ceramic microfiltration membrane fouled with a whey protein concentrate. Membrane performance and cleaning efficiency, Food and Bioproducts Processing. 82 (2004) 231-243. https://doi.org/10.1205/fbio.82.3.231.44182.

[11] G. Daufin, U. Merin, F.L. Kerherve, J.P. Labbe, A. Quemerais, C. Bousser, Efficiency of cleaning agents for an inorganic membrane after milk ultrafiltration, Key Engineering Materials. 61-62 (1991) 553-556. https://doi.org/10.4028/www.scientific.net/kem.61-62.553.

[12] R. Field, D. Hughes, Z. Cui, U. Tirlapur, Some observations on the chemical cleaning of fouled membranes, Desalination. 227 (2008) 132-138. https://doi.org/10.1016/j.desal.2007.08.004.

[13] C. Regula, E. Carretier, Y. Wyart, G. Gésan-Guiziou, A. Vincent, D. Boudot, P. Moulin, Chemical cleaning/disinfection and ageing of organic UF membranes: A review, Water Research. 56 (2014) 325-365. https://doi.org/10.1016/j.watres.2014.02.050.

[14] E. Arkhangelsky, D. Kuzmenko, V. Gitis, Impact of chemical cleaning on properties and functioning of polyethersulfone membranes, Journal of Membrane Science. 305 (2007) 176-184. https://doi.org/10.1016/j.memsci.2007.08.007.

[15] A. Weis, M.R. Bird, M. Nyström, The chemical cleaning of polymeric UF membranes fouled with spent sulphite liquor over multiple operational cycles, Journal of Membrane Science. 216 (2003) 67-79. https://doi.org/10.1016/S0376-7388(03)00047-4.

[16] A. Weis, M.R. Bird, M. Nyström, C. Wright, The influence of morphology, hydrophobicity and charge upon the long-term performance of ultrafiltration membranes fouled with spent sulphite liquor, Desalination. 175 (2005) 73-85. https://doi.org/10.1016/j.desal.2004.09.024.

[17] H. Zhu, M. Nyström, Cleaning results characterized by flux, streaming potential and FTIR measurements, Colloids and Surfaces A: Physicochemical and Engineering Aspects. 138 (1998) 309-321. https://doi.org/10.1016/S0927-7757(97)00072-1. 
[18] D. Wu, M.R. Bird, The fouling and cleaning of ultrafiltration membranes during the filtration of model tea component solutions, Journal of Food Process Engineering. 30 (2007) 293-323. https://doi.org/10.1111/j.1745-4530.2007.00115.x.

[19] P.J. Evans, M.R. Bird, A. Pihlajamäki, M. Nyström, The influence of hydrophobicity, roughness and charge upon ultrafiltration membranes for black tea liquor clarification, Journal of Membrane Science. 313 (2008) 250-262. https://doi.org/10.1016/j.memsci.2008.01.010.

[20] M. Nyström, H. Zhu, Characterization of cleaning results using combined flux and streaming potential methods, Journal of Membrane Science. 131 (1997) 195-205. https://doi.org/10.1016/S0376-7388(97)00053-7.

[21] M. Pontié, X. Chasseray, D. Lemordant, J.M. Lainé, The streaming potential method for the characterization of ultrafiltration organic membranes and the control of cleaning treatments, Journal of Membrane Science. 129 (1997) 125-133. https://doi.org/10.1016/S03767388(96)00340-7.

[22] M. Pontié, L. Durand-Bourlier, D. Lemordant, J.M. Lainé, Control fouling and cleaning procedures of UF membranes by a streaming potential method, Separation and Purification Technology. 14 (1998) 1-11. https://doi.org/10.1016/S1383-5866(98)00054-9.

[23] J. Zeng, H. Ye, H. Liu, H. Xie, Characterization of a hollow-fiber ultrafiltration membrane and control of cleaning procedures by a streaming potential method, Desalination. 195 (2006) 226234. https://doi.org/10.1016/j.desal.2005.12.003.

[24] A. Szymczyk, P. Fievet, J.C. Reggiani, J. Pagetti, Determination of the filtering layer electrokinetic properties of a multi-layer ceramic membrane, Desalination. 116 (1998) 81-88. https://doi.org/10.1016/S0011-9164(98)00059-9.

[25] N.D. Lawrence, J.M. Perera, M. Iyer, M.W. Hickey, G.W. Stevens, The use of streaming potential measurements to study the fouling and cleaning of ultrafiltration membranes, Separation and Purification Technology. 48 (2006) 106-112. https://doi.org/10.1016/j.seppur.2005.07.009.

[26] A. Al-Amoudi, P. Williams, S. Mandale, R.W. Lovitt, Cleaning results of new and fouled nanofiltration membrane characterized by zeta potential and permeability, Separation and Purification Technology. 54 (2007) 234-240. https://doi.org/10.1016/j.seppur.2006.09.014.

[27] H. Matsumoto, Y. Koyama, A. Tanioka, Interaction of proteins with weak amphoteric charged membrane surfaces: effect of pH, Journal of Colloid and Interface Science. 264 (2003) 82-88. https://doi.org/10.1016/S0021-9797(03)00417-X.

[28] M.Y. Jaffrin, L.H. Ding, Ch. Couvreur, P. Khari, Effect of ethanol on ultrafiltration of bovine albumin solutions with organic membranes, Journal of Membrane Science. 124 (1997) 233-241. https://doi.org/10.1016/S0376-7388(96)00241-4.

[29] N. Smirov, The Annals of Mathematical Statistics, The Annals of Mathematical Statistics. 19 (1948) 279-281. https://doi.org/10.1214/aoms/1177733256.

[30] R.W. Field, D. Wu, J.A. Howell, B.B. Gupta, Critical flux concept for microfiltration fouling, Journal of Membrane Science. 100 (1995) 259-272. https://doi.org/10.1016/03767388(94)00265-Z.

[31] P. Bacchin, P. Aimar, V. Sanchez, Model for colloidal fouling of membranes, AIChE Journal. 41 (1995) 368-376. https://doi.org/10.1002/aic.690410218.

[32] B. Espinasse, P. Bacchin, P. Aimar, Filtration method characterizing the reversibility of colloidal fouling layers at a membrane surface: Analysis through critical flux and osmotic pressure, Journal of Colloid and Interface Science. 320 (2008) 483-490. https://doi.org/10.1016/j.jcis.2008.01.023.

[33] B. Espinasse, P. Bacchin, P. Aimar, On an experimental method to measure critical flux in ultrafiltration, Desalination. 146 (2002) 91-96. https://doi.org/10.1016/S0011-9164(02)00495-2.

[34] D. Kuzmenko, E. Arkhangelsky, S. Belfer, V. Freger, V. Gitis, Chemical cleaning of UF membranes fouled by BSA, Desalination. 179 (2005) 323-333. https://doi.org/10.1016/j.desal.2004.11.078. 
[35] I.N.H.M. Amin, A.W. Mohammad, M. Markom, L.C. Peng, N. Hilal, Flux decline study during ultrafiltration of glycerin-rich fatty acid solutions, Journal of Membrane Science. 351 (2010) 7586. https://doi.org/10.1016/j.memsci.2010.01.033.

[36] R. Zhang, S. Yu, W. Shi, J. Tian, L. Jin, B. Zhang, L. Li, Z. Zhang, Optimization of a membrane cleaning strategy for advanced treatment of polymer flooding produced water by nanofiltration, RSC Adv. 6 (2016) 28844-28853. https://doi.org/10.1039/C6RA01832G.

[37] M.T. Tsehaye, S. Velizarov, B. Van der Bruggen, Stability of polyethersulfone membranes to oxidative agents: A review, Polymer Degradation and Stability. 157 (2018) 15-33. https://doi.org/10.1016/j.polymdegradstab.2018.09.004.

[38] M. Ji, X. Chen, J. Luo, Y. Wan, Improved blood compatibility of polysulfone membrane by anticoagulant protein immobilization, Colloids and Surfaces B: Biointerfaces. 175 (2019) 586595. https://doi.org/10.1016/j.colsurfb.2018.12.026.

[39] E. Smidt, P. Lechner, M. Schwanninger, G. Haberhauer, M.H. Gerzabek, Characterization of Waste Organic Matter by FT-IR Spectroscopy: Application in Waste Science, Appl Spectrosc. 56 (2002) 1170-1175. https://doi.org/10.1366/000370202760295412.

[40] S.G. Salinas-Rodriguez, G.L. Amy, J.C. Schippers, M.D. Kennedy, The Modified Fouling Index Ultrafiltration constant flux for assessing particulate/colloidal fouling of RO systems, Desalination. 365 (2015) 79-91. https://doi.org/10.1016/j.desal.2015.02.018.

[41] B. Malczewska, A. Żak, Structural Changes and Operational Deterioration of the Uf Polyethersulfone (Pes) Membrane Due to Chemical Cleaning, Scientific Reports. 9 (2019) 1-14. https://doi.org/10.1038/s41598-018-36697-2.

[42] J. Marchese, M. Ponce, N.A. Ochoa, P. Prádanos, L. Palacio, A. Hernández, Fouling behaviour of polyethersulfone UF membranes made with different PVP, Journal of Membrane Science. 211 (2003) 1-11. https://doi.org/10.1016/S0376-7388(02)00260-0.

[43] S. Belfer, R. Fainchtain, Y. Purinson, O. Kedem, Surface characterization by FTIR-ATR spectroscopy of polyethersulfone membranes-unmodified, modified and protein fouled, Journal of Membrane Science. 172 (2000) 113-124. https://doi.org/10.1016/S0376-7388(00)00316-1.

[44] S. Sasikala, S. Meenakshi, S.D. Bhat, A.K. Sahu, Functionalized Bentonite clay-sPEEK based composite membranes for direct methanol fuel cells, Electrochimica Acta. 135 (2014) 232-241. https://doi.org/10.1016/j.electacta.2014.04.180.

[45] J. Liu, J. Xiong, X. Ju, B. Gao, L. Wang, M. Sillanpää, Streaming potential for identification of foulants adsorption on PVDF membrane surface, Journal of Membrane Science. 566 (2018) 428434. https://doi.org/10.1016/j.memsci.2018.09.024.

[46] F. Luna-Vera, J.C. Alvarez, Adsorption kinetics of proteins in plastic microfluidic channels: Real-time monitoring of lysozyme adsorption by pulsed streaming potentials, Biosensors and Bioelectronics. 25 (2010) 1539-1543. https://doi.org/10.1016/j.bios.2009.11.002.

[47] P. Blanpain-Avet, J.F. Migdal, T. Bénézech, Chemical cleaning of a tubular ceramic microfiltration membrane fouled with a whey protein concentrate suspension-Characterization of hydraulic and chemical cleanliness, Journal of Membrane Science. 337 (2009) 153-174. https://doi.org/10.1016/j.memsci.2009.03.033.

[48] M.M. Motsa, B.B. Mamba, A.R.D. Verliefde, Combined colloidal and organic fouling of FO membranes: The influence of foulant-foulant interactions and ionic strength, Journal of Membrane Science. 493 (2015) 539-548. https://doi.org/10.1016/j.memsci.2015.06.035.

[49] T. Maruyama, S. Katoh, M. Nakajima, H. Nabetani, T.P. Abbott, A. Shono, K. Satoh, FT-IR analysis of BSA fouled on ultrafiltration and microfiltration membranes, Journal of Membrane Science. 192 (2001) 201-207. https://doi.org/10.1016/S0376-7388(01)00502-6. 